\title{
Expiratory Flow Limitation and the Response to Breathing a Helium-Oxygen Gas Mixture in a Canine Model of Pulmonary Emphysema
}

Steven N. Mink

Section of Respiratory Diseases, University of Manitoba, Winnipeg, Manitoba, R3E 0Z3; University of Texas Health Science Center at San Antonio, Texas 78284

bstract. The pathophysiology of reduced maximum expiratory flow in a canine model of pulmonary emphysema was studied, and the results interpreted in terms of the wave-speed theory of flow limitation. According to this theory, maximum expiratory flow is related both to the cross-sectional area and compliance at an airway site where a critical gas velocity is first reached ("choke-point") and to gas density. Pulmonary emphysema was produced by the repeated instillations of the enzyme papain into the airways of six dogs. In five control dogs, a saline solution was instilled. During forced vital capacity deflation, in an open-chest preparation, maximum expiratory flow, choke-point locations, and the response to breathing an 80:20 helium/ oxygen gas mixture were determined at multiple lung volumes. To locate choke-points, a pressure measuring device was positioned in the airway to measure lateral and end-on intrabronchial pressures, from which the relevant wave-speed parameters were obtained. In general, the reduced maximum expiratory flow in emphysema can be explained by diminished lung elastic recoil pressure and by altered bronchial pressure-area behavior, which results in a more peripheral location of choke-points that have smaller cross-sectional areas than controls. With respect to the density dependence of maximum expiratory flow, this response did not differ from control values in four dogs with emphysema in which frictional pressure losses upstream from choke-points did not differ on the two gas mixtures. In two dogs with emphysema, however, upstream frictional pressure losses were greater on helium/

Dr. Mink is a Scholar of the Manitoba Health Research Council and a recipient of National Institutes of Health Young Investigator Award. 1984.

Received for publication 27 July 1983 and in revised form 18 January

J. Clin. Invest.

(c) The American Society for Clinical Investigation, Inc.

$0021-9738 / 84 / 05 / 1321 / 14 \quad \$ 1.00$

Volume 73, May 1984, 1321-1334 oxygen than on air, which resulted in a smaller crosssectional area on helium/oxygen; hence density dependence decreased.

\section{Introduction}

Changes in the mechanical properties of the lung in pulmonary emphysema (PE) include a reduction in the elastic recoil pressure $(P e l)$ of the lung $(1,2)$, an increase in airway resistance (3), and alterations in bronchial pressure-area behavior $(4,5)$. These changes result in a decrease in maximum expiratory flow $(\dot{V} \max )$. In previous studies, the pathophysiology of reduced $\dot{V}$ max in PE has been examined in terms of theories of flow limitation, which are based on conceptual analyses. These included "equal pressure point" theory or theories based on the concept of a flow-limiting segment (6-9). However, recent evidence suggests that in healthy lungs $\dot{V}$ max may be explained in terms of wave-speed theory $(10,11)$. According to this theory, flow becomes limited when at a site in the airway, the chokepoint, tube wave-speed is reached. At the choke-point, gas velocity is equal to the speed of propagation of pressure pulse waves along the airway wall. Each bronchial cross-section can develop a choke-point, and $\dot{V} \max$ will be reached at the lowest value at which tube wave-speed occurs in some airway generation. At isovolume conditions, upstream from the choke-point, airway geometry remains constant, and the upstream pressures

1. Abbreviations used in this paper: $A$, airway cross-sectional area; $A *$, cross-sectional area at $\mathrm{CP} ; \mathrm{CP}$, choke points; DLCO, diffusing capacity for $\mathrm{CO}$; EPP, equal pressure points; $\mathrm{FRC}$, functional residual capacity; $K$, airway compliance at $C P ; \mathrm{LLL}$, left lower lobe; $P^{*}$, lateral transmural pressure at $\mathrm{CP} ; \mathrm{PaO}_{2}$, arterial blood $\mathrm{O}_{2}$ tension; $P \mathrm{ca}$, convective acceleration; $\mathrm{PE}$, pulmonary emphysema; $P_{\mathrm{E}^{*}}$, transmural end-on pressure at $\mathrm{CP} ; P$ el, elastic recoil pressure; $P$ end, pressure measured from the end-on port of Pitot-static tube; $P$ fr, frictional pressure drop; $P_{\mathrm{L}}$, transpulmonary pressure; Plat, pressure measured from the lateral port of Pitot-static tube; $P$ pl, pleural surface pressure; $P$ ret, lateral airway pressure measured with the retrograde catheter; $R_{\mathrm{L}}$, airway resistance at FRC; $\mathrm{RLL}$, right lower lobe; $\mathrm{R} V$, residual volume; TLC, total lung capacity; $V_{\mathrm{L}}$, lung volume; $\dot{V} \max$, maximum expiratory flow; $V_{\mathrm{VH}}, V_{\mathrm{H}}, V_{\mathrm{M}}$, and $V_{\mathrm{LL}}$, very high, high, middle, and low lung volumes, respectively; VC, vital capacity. 
are unchanged when the driving pressure changes; downstream, however, the pressure drop along the airway increases due to formation of a flow-limiting segment where energy is dissipated. At a given lung volume $\left(V_{\mathrm{L}}\right)$, the factors that determine chokepoint area and site are $P$ el and the distributions along the airway of viscous pressure losses and airway compliances (12). $\dot{V} \max$ is given by $\dot{V} \max =\left(A * *^{3} / \rho \mathrm{q} K\right)^{1 / 2}$, where $A *$ and $K$ are airway area and compliance at the choke-point, respectively, $\rho$ is gas density, and $\mathrm{q}$ is a correction factor for departure from blunt velocity profile.

Accordingly, in PE, interpreting how changes in lung mechanical properties may affect $\dot{V}$ max would depend upon the relative changes in airway area and compliance at the chokepoint. In previous experiments, choke-points or flow-limiting sites (CP) were identified at $\sim 50 \%$ vital capacity (VC) in canine and human lungs $(13,14)$. In the present experiment, PE was produced in dogs by the repeated instillations of the enzyme papain into their airways. Papain has been shown to produce in canine lungs histological and mechanical changes of panacinar emphysema (15). The changes produced are identical to those found in patients who have pulmonary emphysema due to alpha-1-anti-trypsin deficiency. The effect of PE on CP location, $\dot{V} \max$, and the pressure drop from alveoli to $\mathrm{CP}$ was studied.

The response $\left\{\Delta \dot{V} \max =\left(\dot{V} \max \mathrm{He} / \mathrm{O}_{2}-\dot{V} \max\right.\right.$ air $) \times 100 /$ $\dot{V} \max$ air $\}$ to breathing the less dense gas mixture 80:20 helium/ oxygen $\left(\mathrm{He} / \mathrm{O}_{2}\right)$ was also determined. The magnitude of this response is thought to be clinically useful in determining the relative location of the flow-limiting site. According to contemporary theory, with the flow-limiting site located peripherally, $\Delta \dot{V}$ max would decrease (16). At a more peripheral location, the convective pressure drop and turbulent frictional pressure losses from alveoli to $\mathrm{CP}$, both of which are density dependent, would relatively decrease, whereas the density-independent frictional losses would relatively increase. In view that the response to breathing $\mathrm{He} / \mathrm{O}_{2}$ may have clinical significance in assessing $\mathrm{PE}$, this response was also obtained in the model, and the results interpreted in wave-speed terms.

\section{Methods}

Emphysema model. PE was produced in six dogs (group E) by the intrabronchial administration of the enzyme papain. Papain was administered analagously to the administration described by Takaro and McWhite (17). Six mongrel dogs (group E) weighing 25-30 kg were anesthetized with sodium pentobarbital $(30 \mathrm{mg} / \mathrm{kg})$ and then intubated with an endotracheal tube. Under bronchoscopic visualization, $4 \mathrm{~cm}^{3}$ of the enzyme papain (type III; Sigma Chemical Co., St. Louis, MO), mixed in $40 \mathrm{~cm}^{3}$ of sterile normal saline solution, were placed into their right or left lower lobe bronchi. This procedure was repeated at weekly intervals for $7 \mathrm{wk}$, and the instillations were altered between the lobes. Four doses were placed into the right lower lobe (RLL) and three into the left lower lobe (LLL). After each instillation, the animals were positioned with the instilled lobe placed dependently and mechanically ventilated $20 \mathrm{~cm}^{3} / \mathrm{kg}$ ), while receiving $50 \%$ oxygen for $\sim 6 \mathrm{~h}$. Given in this dose and manner, it was noted in preliminary experiments that the papain mixture spread diffusely through the upper and lower lobes on the inoculated side, but did not compromise oxygenation by significantly spreading to the contralateral lung. In five control animals (group C), $40 \mathrm{~cm}^{3}$ of normal saline solution was used; otherwise the protocol was the same. All animals received antibiotics (penicillin and gentamicin) before each inoculation and for every $12 \mathrm{~h}$ thereafter for a total of four doses to prevent bacterial infection.

General measurements. Measurements of static lung mechanics and respiratory gas exchange were made before the initial dose of the enzyme and $2 \mathrm{wk}$ after the final one ( $\sim 3$ mo later). These measurements were obtained with the animals anesthetized, intubated with an endotracheal tube, and mechanically ventilated; the inspirate was room air. Determinations of total lung capacity (TLC), functional residual capacity (FRC), and residual volume ( $\mathrm{R} V$ ) were made in a volume displacement plethysmograph, after an esophageal balloon was inserted. These measurements were performed similarly to those previously described (18). In the left lateral decubitus position, FRC was performed by the method of DuBois et al. (19). The lungs were then deflated to a transpulmonary pressure $\left(P_{\mathrm{L}}\right)$ of $-10 \mathrm{~cm} \mathrm{H}_{2} \mathrm{O}(\mathrm{RV})$ with a 1.5 -liter volume syringe, after which they were inflated to a $P_{\mathrm{L}}$ of $30 \mathrm{~cm} \mathrm{H}_{2} \mathrm{O}$ (TLC) with a positivepressure source. After a TLC volume history, airway resistance at FRC $\left(\mathrm{R}_{\mathrm{L}}\left[\mathrm{cm} \mathrm{H}_{2} \mathrm{O} /\right.\right.$ liters $\left.\left.\cdot \mathrm{s}\right]\right)$ was determined by the oscillation technique of Mead and Whittenberger (20). The frequency used was $4 \mathrm{~Hz}$, and peakto-peak flow rates were 1 liter/s. Respiratory gas-exchange parameters were also obtained. These included measurements of arterial blood oxygen tension $\left(\mathrm{PaO}_{2}\right)$ and the diffusing capacity for carbon monoxide (DLCO). $\mathrm{PaO}_{2}$ was measured with a blood gas analyzer (Corning Medical, Corning Glass Works, Medfield, MA). DLCO was estimated by the rebreathing technique of Lewis et al. (21). Carbon monoxide concentrations were measured with a mass spectrometer. The animals were returned to their cages after these measurements.

Parameters of maximum expiratory flow. Parameters of forced expiration were obtained 2 wk after the second set of gas exchange and mechanics measurements ( $\sim-4 \mathrm{wk}$ after the last dose of enzyme). As before, the animals were anesthetized with sodium pentobarbital (30 $\mathrm{mg} / \mathrm{kg})$ and artificially ventilated $\left(20 \mathrm{~cm}^{3} / \mathrm{kg}\right)$. Their chests were then widely opened, and their tracheas were cannulated with a large-bore steel tracheal tube. The distal end of the tracheal tube just extended $(\sim 2 \mathrm{~cm})$ into the thoracic inlet. Measurements were obtained with the animals placed into the plethysmograph in the supine position.

To obtain lung recoil pressures $(\mathrm{Pel})$, static pressure-volume curves were obtained, in which lung volume was measured by a Krogh spirometer mounted on the rear of the plethysmograph $(13,14$, see Fig. 1). However, to obtain lung volume when dynamic parameters were recorded, a signal proportional to integrated flow was used (Validyne Integrator, model FV 156; Validyne Engineering Corp., Northridge, CA). The flow signal was obtained from a large pneumotachograph (Hans-Rudolph, Inc., Kansas City, MO) mounted between the Krogh spirometer and the plethysmograph. Signals proportional to flow and transmural airway pressures (see below) were displayed on two ordinates of a dual beam oscilloscope (Tektronix, Inc., Beaverton, OR), while lung volume, either static or dynamic, was displayed on the abscissa. The frequency responses of the flow and volume (integrated flow) signals were adequate in phase and amplitude to $\sim 15 \mathrm{~Hz}$. In the plethysmograph, the lung could be inflated with a positive pressure source or forcibly deflated by applying negative pressure to the airway opening.

A Pitot-static tube was used to locate $\mathrm{CP}$ and to measure airway pressures. It was pointed down the right or left lower lobe (see Fig. 1). The Pitot-static tube was constructed similarly to those reported elsewhere (22-24), and the lateral (Plat) and end-on (Pend) pressure ports on the 


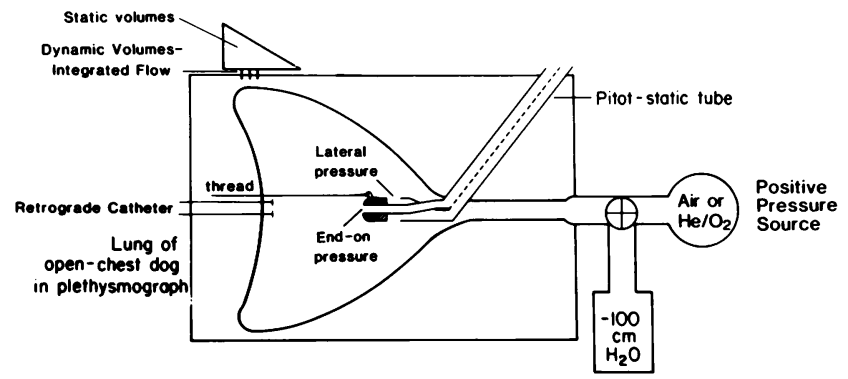

Figure 1. Schematic drawing of the experimental apparatus. Static lung volumes were measured by a Krogh spirometer mounted on the plethysmograph. When dynamic lung volumes were recorded, a signal proportional to integrated flow was used. A Pitot-static tube and retrograde catheter were placed into the same airway, as described in the text. When the string at the pleural surface was pulled, the Pitotstatic tube could be advanced down the airway and its longitudinal axis maintained in the proper position. The retrograde catheter was also pulled along the airway by a string (not shown in the figure, for clarity). Lateral (Plat) and end-on (Pend) pressures were measured from the respective ports of the Pitot-static tube. With the retrograde catheter, lateral pressure (Pret) was recorded. Airway pressures were referenced to pleural surface pressure $(P \mathrm{pl})$, measured with an identical catheter positioned adjacent to the lung (not shown). At a given $V_{\mathrm{L}}$, to identify $\mathrm{CP}$, the tip of the retrograde catheter or the lateral port of the Pitot-static tube was positioned at an airway site at which lateral pressure did not vary with reservoir pressure, but slightly downstream $(<1 \mathrm{~cm})$ transmural airway pressure became relatively more negative and varied with reservoir pressure. For each measurement, the airway was turned into a pressure source that provided vital capacity inflations with either air or $\mathrm{He} / \mathrm{O}_{2}$. Static pressure volume curves were recorded. To obtain maximum expiratory flow, the lungs were opened to a negative pressure source, which forcibly deflated the lungs. Flow volume and dynamic pressure-volume curves were simultaneously recorded. When the gas mixtures were changed, five to six TLC inflations were performed on the newly inspired gas mixture before measurements were obtained. Further, before each measurement, a standard volume history was also given (see text for details).

Pitot-static tube were connected to respective transducers. At a given $V_{\mathrm{L}}$, to locate $\mathrm{CP}$, the lateral port of the Pitot-static tube was positioned at an airway site where specific pressure tracings were observed $(13,14$, $23,24)$. The criteria to locate $C P$ and other aspects of the methodology are described further below (see section on experimental proctocol) Moreover, in three experiments, a retrograde catheter $(13,14,24,25$, see Fig. 1) was additionally used to locate $\mathrm{CP}$ and to measure lateral airway pressures (Pret). Therefore, the results of the retrograde catheter and Pitot-static techniques could be compared. As stated above, the retrograde catheter was only used to obtain airway pressures in three experiments. However, in all experiments, the Pitot-static tube and the retrograde catheter were placed into the same airway, the methodology of which was as follows.

As described by Macklem and Mead (25), a retrograde catheter was first pulled out the pleural surface of the lung. In five experiments (dogs 1-5 and dogs 7-11), the retrograde catheter was placed into the RLL, while in one experiment $(\operatorname{dog} 6)$, it was placed into the LLL. A small string was tied to the retrograde catheter and was also pulled out the pleural surface of the lobe with the retrograde catheter. The other end of the string, which remained in the airway, was then attached to the front end of the Pitot-static tube through a wire loop (see Fig. 1). Accordingly, when the string was pulled at the pleural surface, the Pitotstatic tube could be advanced down the airway, and further, its long axis could be maintained in a correct position in the airway. When they were not in use, the retrograde catheter was wedged into a small airway, and the Pitot-static tube pulled outside the airway.

The lateral and end-on ports of the Pitot-static tube were attached to respective differential pressure transducers (Validyne Engineering Corp.) with polyethylene tubing (length $75 \mathrm{~cm}$, i.d. $1.57 \mathrm{~mm}$ ). Transmural lateral (Plat- $P$ pl) and end-on $(P$ end- $P$ pl) pressures were obtained from the respective ports (24). To obtain transmural airway pressures, these pressures were referenced to pleural surface pressure $(P \mathrm{pl})$, and were measured with an identical catheter located external to the lungs. In view that peribronchial pressure rather than pleural surface pressure would be a more precise estimation of transmural pressure, the use of transmural in this study represents only an approximation. The retrograde catheter (length $90 \mathrm{~cm}$, Clay Adams [New York] PE-205, i.d. $1.57 \mathrm{~mm}$ ) was attached to a similar transducer, and transmural airway pressure $\left(P_{\text {ret- }} P \mathrm{pl}\right)$ was obtained in a similar manner. The frequency responses of the catheter systems were adequate in phase and amplitude to $\sim 12$ $\mathrm{Hz}$. By estimates of the Pitot-static tube in a model system, there were no changes in Plat up to an angle of yaw of at least $35^{\circ} \mathrm{C}$. Also, in comparing the lateral pressure measured with the Pitot-static tube with that from a piezometer ring $\left(2.25 \mathrm{~cm}^{2}\right)$, there were no differences in lateral pressure measurements between the two, with flow rates up to 13 liters per second on air $(23,24)$. The error in measuring lateral airway pressure with the retrograde catheter has been previously described (13).

Numbered markings placed on one of the polyethylene tubes of the Pitot-static tube or on the retrograde catheter were used to identify airway locations. Thus, when the Pitot-static tube or retrograde catheter was appropriately positioned, these values were recorded. For the Pitotstatic tube, the distances were measured from an opening placed in the tracheal tube (24). In the case of the retrograde catheter, the distances were measured from the pleural surface $(13,14)$. At the completion of the experiment, the lungs were excised. The Pitot-static tube was removed from the airway, but the string attached to its front end (see above, and Fig. 1) was left in the airway with its distal end pulled out the pleural surface. The lung was then air-dried for $1 \mathrm{wk}$ at a $P_{\mathrm{L}}$ of $20 \mathrm{~cm} \mathrm{H}_{2} \mathrm{O}$, after which the tracheobronchial tree was dissected along the route delineated by the string. The specific locations of $\mathrm{CP}$ with respect to airway generation and diameter were determined.

Experimental protocol. $\mathrm{CP}$ were identified by criteria previously described $(13,14,24)$. At a given lung volume, the tip of the retrograde catheter or the lateral port of the Pitot-static tube was positioned at an airway site where the lateral pressure that was measured did not vary with negative pressure applied to the airway opening, but slightly downstream $(<1 \mathrm{~cm})$ respective measurements of $P$ ret- $P$ pl or $P$ lat- $P$ pl decreased abruptly and varied with negative pressure applied to the airway opening. Lateral transmural airway pressure at $\mathrm{CP}$ was designated $\mathrm{P} *$. With the Pitot-static tube positioned at $\mathrm{CP}$, the dynamic pressure recorded from the end-on port (Pend-Ppl) was also obtained. This measurement was designated $P_{\mathrm{E}^{*}}$. CP were identified at four lung volumes in each group. These approximated $65 \% \mathrm{VC}$, designated $V_{\mathrm{VH}}$ for very high; $50 \% \mathrm{VC}$, designated $V_{\mathbf{H}}$ for high; $30 \% \mathrm{VC}$, designated $V_{\mathrm{M}}$ for middle; and $15 \%$ $\mathrm{VC}$, designated $V_{\mathrm{LL}}$ for low. Further, lung volumes were also expressed as a percentage of TLC in which a dilution technique was used to determine minimal gas volume. 
The measurement protocol was as follows. To obtain maximum expiratory flow-volume curves, the airway was opened to a negativepressure reservoir. Reservoir pressure was varied (from $-50 \mathrm{mmHg}$ to $-220 \mathrm{mmHg}$ ) until the pressure required to achieve $\dot{V} \max$ was identified. The reservoir pressure used in recording $\dot{V}$ max ranged from 25 to $50 \%$ more negative than the minimal pressure required to achieve maximal forced expiration. For each of the designated lung volumes, the Pitotstatic tube or retrograde catheter was positioned at $\mathrm{CP}$ and its location was recorded. The number of forced expirations required to identify $\mathrm{CP}$ at a given lung volume was highly variable, but averaged about six. After a volume history of two inflations to TLC $\left(P_{\mathrm{L}}, 30 \mathrm{~cm} \mathrm{H}_{2} \mathrm{O}\right)$, on the subsequent inflation the airway was opened to the negative-pressure source. Forced expiratory Plat or Pret-Ppl-lung volume and flow-volume curves were recorded on the oscilloscope. With the Pitot-static tube, $P$ end-Ppl-lung volume curves, with corresponding flow-volume curves, were also obtained. Quasi-static pressure volume curves $\left(P e l-V_{L}\right)$ were additionally recorded in which the flow rate during these curves was maintained at $<100 \mathrm{~cm}^{3} / \mathrm{s}$. Two curves of each pressure and flow parameter were obtained; their results were photographed and averaged. Further, with the Pitot-static tube, airway compliance $(K)$ at $\mathrm{CP}$ at each $V_{\mathrm{L}}$ was estimated. This estimation was performed within the framework of the following rationale.

The difference between $P$ lat- $P \mathrm{pl}$ and $P$ end- $P \mathrm{pl}$ is related to the kinetic energy of the gas passing the cross-section $A$ and is termed convective acceleration (Pca). $P$ ca $=1 / 2 \rho \dot{V} \max ^{2} / A^{2}$, where $A$ is cross-sectional area and $\rho$ is gas density (values used are given in data analysis). At a given $V_{\mathrm{L}}, K$ was estimated. $P$ lat- $P \mathrm{pl}$ and $P$ end- $P \mathrm{pl}$ were measured at $\mathrm{CP}$ and slightly upstream $(\sim 1 \mathrm{~cm})$ from $\mathrm{CP}(24)$. The cross-sectional area at CP $(A *)$ and the area slightly upstream $(A)$ were then calculated from the $P$ ca equation in which the the respective variables measured at the two airway sites were used. The change in $A$ related to the change in $P$ lat- $P \mathrm{pl}$ at the two sites gave an approximate estimate of airway compliance: $K=(A-A * / P-P *)$. This estimation was thus performed with the hope that the area-pressure relationship did not differ between the two sites. In some experiments, however, estimates of $P c a$ in upstream airway sites were not measurably different from those at $\mathrm{CP}$ or were too small to measure. $K$ could not be calculated when this occurred, because $\Delta A$ could not be ascertained. In those instances, to obtain $K$ an estimation similar to that described by Pedersen et al. was used (23). In this technique, the Pitot-static tube was positioned at $\mathrm{CP}$ at a given $V_{L}$. Plat-Ppl and Pend-Ppl were obtained at lung volumes slightly higher $\left(100 \mathrm{~cm}^{3}\right)$ and lower $\left(100 \mathrm{~cm}^{3}\right)$ than the $V_{\mathrm{L}}$ at which the $\mathrm{CP}$ was determined. The respective airway areas at the higher and lower lung volumes were again calculated from the $P$ ca equation. The change in cross-sectional area (i.e., higher minus the lower) divided by the corresponding change in Plat-Ppl gave an estimate of $K$. In effect, over a limited range of recoil pressures, a transmural pressure-area plot of the bronchus could be obtained that reflected bronchial behavior at the $P *$ measured. Even with this technique, however, if Plat-Ppl or area did not change appreciably over the higher and lower lung volumes, $K$ could not be calculated. Thus, there were instances when neither technique could be used. In individual experiments, when the two techniques were compared, both gave similar results.

All measurements were repeated while breathing $80: 20 \mathrm{He} / \mathrm{O}_{2} . \mathrm{CP}$ were identified at the same $V_{\mathrm{L}}$ as on air. To control for the effect of time, measurements obtained while breathing the air and $\mathrm{He} / \mathrm{O}_{2}$ mixtures were alternated. Five to six TLC inflations were performed on the newly inspired gas mixture before measurements were obtained.

Data analysis. The pressure measured from either the lateral port of the Pitot-static tube (Plat-Ppl) or the retrograde catheter (Pret-Ppl) with it positioned at $\mathrm{CP}$ was designated $P_{*}$. The dynamic pressure recorded at this site from the end-on port of the Pitot-static tube (Pend$P \mathrm{pl})$ was $P_{\mathrm{E}^{*}}$. $P_{\mathrm{E}^{*}}$ represents the total pressure or pressure-head at $\mathrm{CP}$ (26). The lateral pressure drop from alveoli to $C P$ is $P$ el- $P *$, and equals the sum of the frictional $(P f r)$ and convective $(P c a)$ pressure drops. The values on each gas were obtained as follows $(23,24,26): P_{\mathrm{E}^{*}}-P_{*}$ $=P \mathrm{ca}$ and $P \mathrm{el}-P_{\mathrm{E}^{*}}=P$ fr, where $P \mathrm{ca}=1 / 2 \rho \dot{V} \max ^{2} / A^{2}$, where $\rho$ is gas density estimated at $1.12 \times 10^{-6} \mathrm{~cm} \mathrm{H}_{2} \mathrm{O} \mathrm{s}^{2} / \mathrm{cm}^{2}$ on air and $0.42 \times 10^{-6}$ $\mathrm{cm} \mathrm{H}_{2} \mathrm{O} \mathrm{s} / \mathrm{cm}^{2}$ on $\mathrm{He} / \mathrm{O}_{2}$ and $A$ is bronchial cross-sectional area (13, 14). With this equation, therefore, $A$ on each gas could be computed.

Samples of tissue were taken from the upper and both lower lobes and were sent for histological examination.

Tests for statistical significance included a two-way analysis of variance with repeated measures and a multiple range comparison test (Tukey's) for significant differences between the parameters.

\section{Results}

Histological samples of lung tissue taken at the end of the experiments showed that all the animals in group $E$ had pathological changes of severe pan-acinar emphysema. Samples showed extensive hyperinflation of distal airspaces and evidence of parenchymal destruction. These findings were obtained whether the samples were taken from the upper or lower lobes. Group $\mathrm{C}$ animals showed no pathological findings. Base-line parameters of lung mechanics and gas exchange made with the chest intact were similar in the two groups. Compared with base-line measurements, TLC and FRC increased $\sim 40 \%$ in group $\mathrm{E}$, while $\mathrm{R} V$ increased $\sim 140 \%$. As measured from a transpulmonary pressure of $5 \mathrm{~cm} \mathrm{H}_{2} \mathrm{O}$ to $\mathrm{FRC}$, deflation compliance also increased in group $\mathrm{E}\left(339 \pm 97 \mathrm{ml} / \mathrm{cm} \mathrm{H}_{2} \mathrm{O}\right.$ at base line vs. $436 \pm 91 \mathrm{ml} / \mathrm{cm} \mathrm{H}_{2} \mathrm{O}$ after papain, $P<0.05$ ). Compared with group $\mathrm{C}, R_{\mathrm{L}}$ was higher in group $\mathrm{E}$, but was not significantly different $\left(3.46 \pm 2.26 \mathrm{~cm} \mathrm{H} \mathrm{H}_{2} \mathrm{O} /\right.$ liters $\cdot \mathrm{s}$ in group $\mathrm{E}$ vs. $1.45 \pm 0.3$ $\mathrm{cm}_{2} \mathrm{O}$ /liters $\cdot \mathrm{s}$ in group $\mathrm{C}, 1.0<P>0.05$ ). In group $\mathrm{E}$, DLCO decreased $\sim 40 \%$ from base line, and mean $\mathrm{PaO}_{2}$ averaged $69 \pm 3$ $\mathrm{mmHg}$. In group $\mathrm{C}$, there were no significant changes in lung mechanics or gas exchange, and $\mathrm{PaO}_{2}$ averaged $97 \pm 4 \mathrm{mmHg}$.

The $V_{\mathrm{L}}$ at which $\mathrm{CP}$ were identified in each group are shown in Table I, expressed as percentages of VC and TLC. As measured in the open-chest preparation, minimal gas volume increased in group $E$ and averaged $0.75 \pm 0.24$ liters compared with $0.33 \pm 0.10$ liters in group $C(P<0.01)$. Mean VC averaged $3.2 \pm 0.6$ liters in group $E$ and $2.6 \pm 0.6$ liters in group $C$. At the respective $V_{\mathrm{L}}$, in group $\mathrm{E}, P$ el decreased to about one-half that found in group $C$. These changes were statistically different at $V_{\mathrm{VH}}$ and $V_{\mathrm{H}}$ and approached statistical significance $(P=0.06)$ at $V_{\mathrm{M}}$ and $V_{\mathrm{LL}}$. Mean $( \pm) \mathrm{Pel}$ in the two groups on air are shown in Table II. The flow-volume curves on air (and $\mathrm{He} / \mathrm{O}_{2}$ ) in groups $\mathrm{E}$ and $\mathrm{C}$ are shown in Figs. 2 and 3, respectively. The vertical stippled lines indicate the $V_{\mathrm{L}}$ where $\mathrm{CP}$ were identified. Note the expanded scale on the ordinate in Fig. 2 and the marked change in the configuration of the flow-volume curve, which in the emphysematous group (Fig. 2) had a more humanoid appearance. The mean $( \pm)$ values of $\dot{V} \max$ on air in each group at the four $V_{\mathrm{L}}$ are shown in Table II. In group $\mathrm{E}$, 
Table I. Lung Volumes $\left(V_{L}\right)$ at Which Choke Points Were Identified

\begin{tabular}{lll}
\hline$V_{\mathrm{L}}$ & $\% \mathrm{TLC}$ & $\% \mathrm{VC}$ \\
\hline & mean $\pm S D$ & mean $\pm S D$ \\
Group E & & \\
$V_{\mathrm{VH}}$ & $72 \pm 4$ & $66 \pm 6$ \\
$V_{\mathrm{H}}$ & $60 \pm 4$ & $49 \pm 3$ \\
$V_{\mathrm{M}}$ & $46 \pm 6$ & $33 \pm 8$ \\
$V_{\mathrm{LL}}$ & $34 \pm 5$ & $18 \pm 3$ \\
Group C & & \\
$V_{\mathrm{VH}}$ & $66 \pm 8$ & $61 \pm 10$ \\
$V_{\mathrm{H}}$ & $55 \pm 4$ & $48 \pm 5$ \\
$V_{\mathrm{M}}$ & $36 \pm 5$ & $28 \pm 6$ \\
$V_{\mathrm{LL}}$ & $26 \pm 8$ & $16 \pm 8$ \\
\hline
\end{tabular}

at the respective $V_{\mathrm{L}}, \dot{V} \max$ decreased to less than one-third that observed in group $C$.

Fig. 4 shows the CP positions on air in the two groups. In group $\mathrm{C}, \mathrm{CP}$ were identified at the trachea at the two higher $V_{\mathrm{L}}$ and at the entrance to the RLL bronchus at the two lower $V_{L}$. Mean bronchial diameters obtained in the air-dried lungs averaged $2.0 \pm 0.2 \mathrm{~cm}$ at $V_{\mathrm{VH}}$ and $V_{\mathrm{H}}$ and $1.4 \pm 0.4 \mathrm{~cm}$ at $V_{\mathrm{M}}$ and $V_{\mathrm{LL}}$. In group $\mathrm{E}$, in dogs $1-5, \mathrm{CP}$ were identified just upstream to RLL lobar bronchi and were generally found at the confluence of multiple segmental bronchi $(1 \mathrm{~cm}$ diam). In dog 6 , measurements were obtained from the LLL, and the results were similar. In $\operatorname{dog} 6$, at the three highest $V_{\mathrm{L}}, \mathrm{CP}$ were identified at


per Second]) and Relevant Pressure Measurements on Air in Groups $E$ and $C$

\begin{tabular}{llrlr}
\hline$V_{\mathrm{L}}$ & \multicolumn{1}{l}{$\dot{V e l}_{\max }$} & $P_{\mathrm{E}^{*}}$ & \multicolumn{1}{l}{$P^{*}$} \\
\hline Group E & & & & \\
$V_{\mathrm{VH}}$ & $4.5 \pm 0.8^{*}$ & $3.9 \pm 2.5^{*}$ & $3.3 \pm 4.7$ & $-2.0 \pm 7.1^{*}$ \\
$V_{\mathrm{H}}$ & $3.7 \pm 1.4^{*}$ & $1.9 \pm 1.0^{*}$ & $2.8 \pm 2.3$ & $0.4 \pm 2.3^{*}$ \\
$V_{\mathrm{M}}$ & $2.8 \pm 1.5$ & $1.1 \pm 0.6^{*}$ & $2.4 \pm 1.5$ & $0 \pm 1.5$ \\
$V_{\mathrm{LL}}$ & $1.6 \pm 0.7$ & $0.5 \pm 0.2^{*}$ & $1.1 \pm 1.0$ & $-0.5 \pm 0.9$ \\
Group C & & & & \\
$V_{\mathrm{VH}}$ & $10.4 \pm 5.5$ & $12.3 \pm 2.2$ & $4.7 \pm 1.2$ & $-9.4 \pm 4.3$ \\
$V_{\mathrm{H}}$ & $8.0 \pm 3.8$ & $11.3 \pm 2.5$ & $2.7 \pm 1.7$ & $-11.6 \pm 3.0$ \\
$V_{\mathrm{M}}$ & $4.7 \pm 1.9$ & $9.2 \pm 2.0$ & $2.5 \pm 1.0$ & $-0.4 \pm 1.2$ \\
$V_{\mathrm{LL}}$ & $2.9 \pm 1.6$ & $4.7 \pm 2.7$ & $2.0 \pm 0.6$ & $-2.3 \pm 1.5$ \\
\hline
\end{tabular}

$V_{\mathrm{VH}}, V_{\mathrm{H}}, V_{\mathrm{M}}$, and $V_{\mathrm{LL}}$ correspond to lung volumes $\left(V_{\mathrm{L}}\right)$ at which $\mathrm{CP}$ were identified. Groups $\mathrm{E}$ and $\mathrm{C}$ are emphysema and control groups, respectively. $P_{*}$ and $P_{\mathrm{E}^{*}}$ are lateral and end-on pressures respectively measured with the Pitot-static tube $\left(\mathrm{cm} \mathrm{H}_{2} \mathrm{O}\right.$, mean $\left.\pm \mathrm{SD}\right)$.

$* P<0.01$, group $\mathrm{E}$ vs. group $\mathrm{C}$. the confluence of segmental bronchi (1-cm diam), while at $V_{\mathrm{LL}}$, $\mathrm{CP}$ were identified in segmental bronchi $(0.6-\mathrm{cm}$ diam). Dog 4 had the highest $P$ el at $V_{\mathrm{VH}}$, and $\mathrm{CP}$ at this $V_{\mathrm{L}}$ were identified at the trachea as in group C. In dog 5, CP at $V_{\mathrm{VH}}$ were located slightly upstream compared with those at the other $V_{\mathrm{L}}$. The only experiment in which CP on air moved appreciably upstream at $V_{\mathrm{M}}$ and $V_{\mathrm{LL}}$ was with $\operatorname{dog} 1$, while with $\operatorname{dog} 6$ there was some upstream movement at $V_{\mathrm{LL}}$. For the most part, however, $\mathrm{CP}$ were found at sublobar bronchi over most of the vital capacity.

In the individual experiments, the dynamic pressure-volume curves obtained with the Pitot-static tube positioned at $\mathrm{CP}$ are shown in the lower panels of Fig. 2 (group E) and Fig. 3 (group C). These figures are described as follows. In the individual panels, the vertical stippled lines indicate the $V_{\mathrm{L}}$ at which $\mathrm{CP}$ were found at the position of the Pitot-static tube. The most peripheral positions are described by the curves at the bottom of the figure. In both groups, CP were often located at the same airway site at more than one $V_{L}$. This finding is indicated in the figures by multiple stippled lines in a panel. In the figures, both ( $P$ lat- $P$ pl)- $V_{\mathrm{L}}$ and ( $P$ end- $P$ pl)- $V_{\mathrm{L}}$ curves are drawn. The lower curves represent those of $P$ lat- $P$ pl, which are shown by the solid lines; the upper lines represent those of Pend-Ppl, which are indicated by the dashed lines. At the $V_{L}$ indicated by the vertical stippled lines, the respective transmural airway pressures represent $P_{*}$ and $P_{\mathrm{E}}$. Also, as shown in Fig. 4, in many experiments $\mathrm{CP}$ were identified at the same airway number at multiple $V_{\mathrm{L}}$. Often, however, in these instances, the Pitotstatic tube was moved a small distance in identifying CP at the various $V_{\mathrm{L}}$. Thus, individual dynamic pressure-volume curves could be obtained at several different airway positions at the same airway number. For instance, in dog 10 (see Fig. 3) at $V_{M}$ and $V_{\mathrm{LL}}, \mathrm{CP}$ were identified at two airway locations $\sim 1 \mathrm{~cm}$ apart. At both $V_{\mathrm{L}}, \mathrm{CP}$ were in airway No. 4 (see Fig. 4).

The mean values of $P *$ and $P_{\mathrm{E}} *$ on air are shown in Table II. Compared with group $\mathrm{C}$, in group $\mathrm{E}, P *$ became more positive at $V_{\mathrm{VH}}$ and $V_{\mathrm{H}}$. Recall that at these $V_{\mathrm{L}}$, there was shift of $\mathrm{CP}$ from the trachea to sublobar bronchi. At $V_{\mathrm{M}}$ and $V_{\mathrm{LL}}, P_{*}$ was just slightly more positive or the same as it was in group C. At these $V_{\mathrm{L}}$, there was only slight upstream movement of CP. Mean $P_{\mathrm{E}^{*}}$ on air at the respective $V_{\mathrm{L}}$ are also shown in Table II. In group $\mathrm{E}$, mean $P_{\mathrm{E}} *$ were slightly lower or equal to those in group $\mathrm{C}$, although $\mathrm{CP}$ were more peripherally located in group E. From the respective values of $P$ el $-P_{\mathrm{E}} *$ and $P_{\mathrm{E}} *$ $-P *$ (see data analysis), $P$ fr and $P$ ca from alveoli to CP were calculated. In the two groups, the respective values on air at the four $V_{\mathrm{L}}$ are shown in Table III. In both groups, $P$ ca accounted for over one-half of the total pressure drop from alveoli to $\mathrm{CP}$ $(P$ el-P*) (see Table II).

From the values of $P \mathrm{ca}$, estimates of $A *$ were made. Table IV shows these values on air. Compared with group $\mathrm{C}, A$ * decreased at the respective $V_{\mathrm{L}}$ in group $\mathrm{E}$. At $V_{\mathrm{VH}}$, the decrease was from $2.5 \mathrm{~cm}^{2}$ to $1.35 \mathrm{~cm}^{2}$, and at $V_{\mathrm{LL}}$ the decrease was from $1.76 \mathrm{~cm}^{2}$ to $0.34 \mathrm{~cm}^{2}$. Further, in group $\mathrm{E}$, as $A^{*}$ decreased with lung volume from $1.35 \mathrm{~cm}^{2}$ to $0.34 \mathrm{~cm}^{2}, \dot{V}$ max decreased 


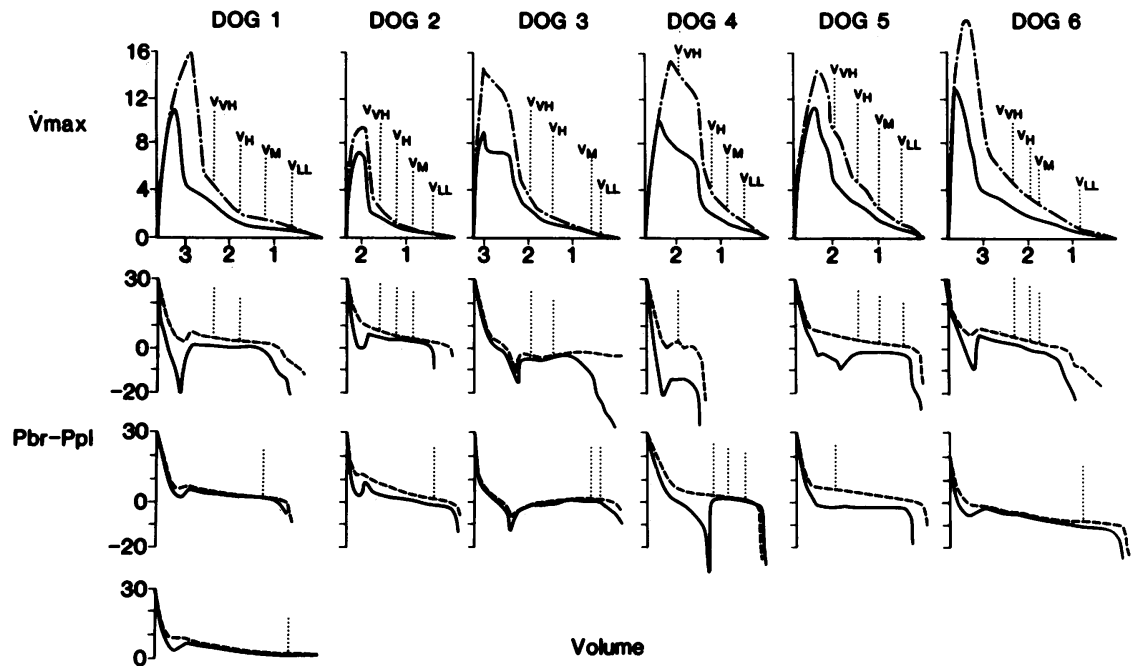

Figure 2. Flow-volume (upper panel) and pressure-volume (lower panels) curves of the individual dogs in group $\mathrm{E}$ are shown. In the upper panel, maximum expiratory flow (V́max) (liters per second) is plotted on the ordinate against lung volume (liters) on the abscissa. Flow-volume curves on air are shown by the solid lines while those on $\mathrm{He} /$ $\mathrm{O}_{2}$ are indicated by (- - - The vertical stippled lines indicate the lung volumes at which choke-points were identified. The $V_{\mathrm{L}}\left(V_{\mathrm{VH}}, V_{\mathrm{H}}, V_{\mathrm{M}}, V_{\mathrm{LL}}\right)$ corresponded to $\sim 65,50,35$, and $15 \% \mathrm{VC}$, respectively. In the lower panels, transmural airway pressure $(P b r-P p l)\left(\mathrm{cm} \mathrm{H}_{2} \mathrm{O}\right)$ is plotted on the ordinate against lung volume (liters) on the abscissa. The results shown were obtained on air. The vertical stippled lines again indicate the $V_{\mathrm{L}}$ at which choke points were found at

the position of the Pitot-static tube. The most peripheral positions are described by the curves at the bottom of the figure. In the panels, the lower curves are those of Plat- $P \mathrm{pl}-V_{\mathrm{L}}(-)$, and the upper curves are those of Pend-Ppl $-V_{\mathrm{L}}(-----)$. With the Pitot-static tube properly positioned, the respective measurements represented $P *$ and $P_{\mathrm{E}^{*}}$. See text for discussion.

from 3.9 to 0.5 liters per s. This decrease occurred with just slight upstream movement of CP. Estimates of airway compliance on air are also shown in Table IV. In group C, on the mean, values of $K$ increased when CP shifted from the trachea to just upstream from lobar bronchi. Compared with group $\mathrm{C}$, $K$ increased but not significantly at $V_{\mathrm{VH}}$ and $V_{\mathrm{H}}$ in group E. At these $V_{\mathrm{L}}, \mathrm{CP}$ shifted from the trachea in group $\mathrm{C}$ to sublobar bronchi in group E. At $V_{\mathrm{M}}, K$ was significantly lower in group
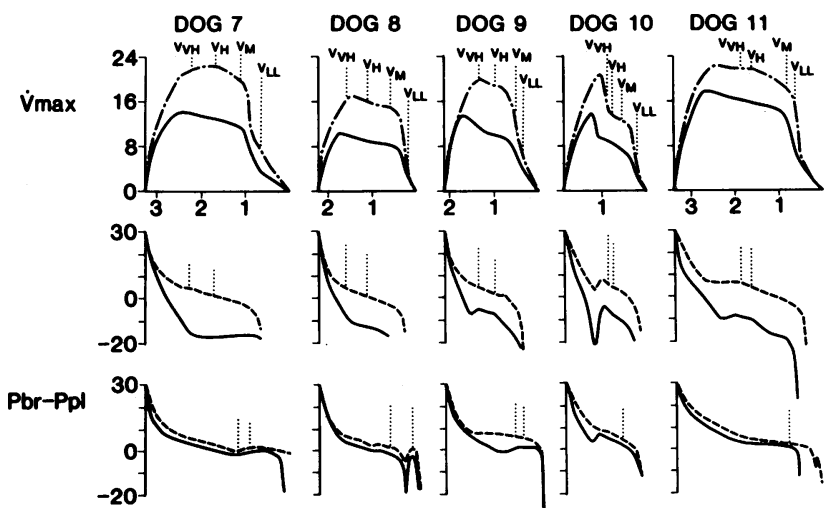

Pbr-Ppl
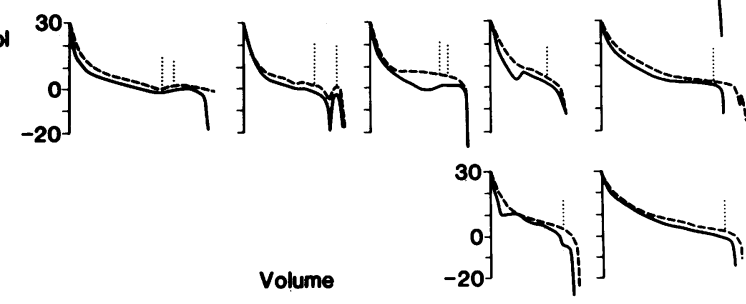

Volume$$
-20 \text { if }
$$

Figure 3. Flow-volume (upper panel) and pressure-volume (lower) curves of the individual dogs in group $\mathrm{C}$ are displayed in a similar manner as in group $\mathrm{E}$. The pressure measurements shown were also obtained on air. See Fig. 2 for legend, and see text for discussion.
E. At $V_{\mathrm{LL}}, K$ could only be calculated in a few experiments in group E. Fig. 5 shows that when at the four $V_{L}$ the respective $A *$ and $K$ in the individual experiments were substituted into the wave-speed equation, there was a relatively good correlation between the measured and predicted $\dot{V}$ max.

In three experiments (dogs 2, 5, and 6), the retrograde catheter was also used to identify CP sites. In dogs 2 and 6, CP were identified at the same airway site when both techniques were compared. In dog 5, CP at each $V_{\mathrm{L}}$ were identified one generation upstream with the retrograde catheter. Lateral airway pressures at $\mathrm{CP}$ were also similar. The mean respective values (Pret- $P \mathrm{pl}$ vs. Plat- $P$ pl) on air were $3.3 \pm 1.1 \mathrm{~cm} \mathrm{H}_{2} \mathrm{O}$ vs. $2.5 \pm 3.1 \mathrm{~cm} \mathrm{H}_{2} \mathrm{O}$ at $V_{\mathrm{VH}}, 1.3 \pm 1.5 \mathrm{~cm} \mathrm{H}_{2} \mathrm{O}$ vs. $1.4 \pm \mathrm{cm} \mathrm{H}_{2} \mathrm{O}$ at $V_{\mathrm{H}}, 1.3 \pm 0.6 \mathrm{~cm}$

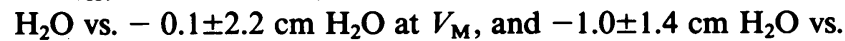
$-0.7 \pm 1.0 \mathrm{~cm} \mathrm{H}_{2} \mathrm{O}$ at $V_{\mathrm{LL}}$. These differences are within the limitations of the techniques.

The responses to breathing $\mathrm{He} / \mathrm{O}_{2}$ are shown in Fig. 6. In group $C, \Delta \dot{V} \max$ averaged $\sim 50-60 \%$ over the $V_{\mathrm{L}}$ measured. Compared with group $\mathrm{C}$, in group $\mathrm{E}$, on the mean, $\Delta \dot{V} \max$ was the same at $V_{\mathrm{VH}}$ and decreased somewhat at the lower $V_{\mathrm{L}}$. There was wide variation in $\Delta \dot{V}_{\max }$ at all $V_{\mathrm{L}}$ in group $\mathrm{E}$, as there was in group $C$ at $V_{M}$ and $V_{\mathrm{LL}}$. There were no significant differences between the groups. In dogs 1 , and 4-6, $\Delta \dot{V}$ max was high over most of the vital capacity. In dogs 2 and 3, however, the increase was much less. For instance, at $V_{\mathrm{H}}$, which approximated $50 \%$ VC, $\Delta \dot{V} \max$ in dogs 2 and 3 were found to be $17 \%$ and $12.5 \%$, respectively. CP on air in dogs 2 and 3 were also identified at sublobar bronchi, the same airway site where in the other experiments. $\Delta \dot{V} \max$ was found to be high. Thus, in individual experiments, different responses to $\mathrm{He} / \mathrm{O}_{2}$ occurred that were apparently independent of $\mathrm{CP}$ locations on air.

In both groups, $\mathrm{CP}$ on air and $\mathrm{He} / \mathrm{O}_{2}$ were identified at the 


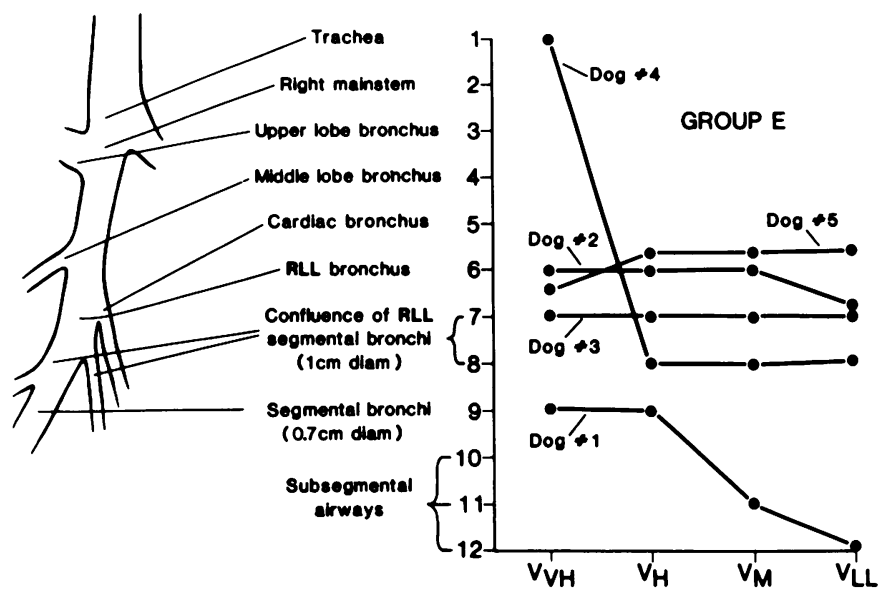

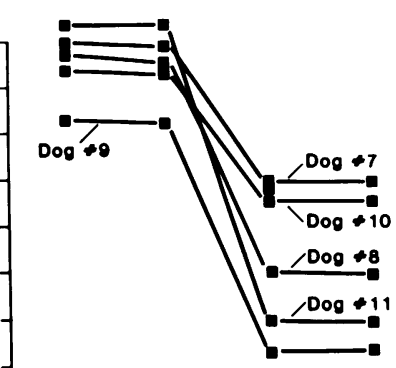

GROUP C

Figure 4. Locations of chokepoints on air in the individual experiments in group $\mathrm{E}$ (left) and group $\mathrm{C}($ right $)$. Numbers on the ordinate refer to the schematic of the canine tracheobronchial tree to indicate the approximate airway site where choke-points were identified. The lung volumes $\left(V_{\mathrm{VH}}\right.$, $V_{\mathrm{H}}, V_{\mathrm{M}}$, and $\left.V_{\mathrm{LL}}\right)$ are shown on the abscissa and corresponded to $\sim 65,50,35$, and $15 \% \mathrm{VC}$, respectively. The tracheobronchial tree of only the right lung is shown, and therefore results in $\operatorname{dog} 6$ are not

shown. In group $\mathrm{E}$, choke-points were identified at the confluence of segmental bronchi (airways 7 and 8 , bronchial diameter averaged 1-cm diameter) over most of the vital capacity. In group C, choke-points were identified at the trachea (airway 1) at $V_{\mathrm{VH}}$ and $V_{\mathrm{H}}$, and at lobar bronchi (airway 6) at $V_{\mathrm{M}}$ and $V_{\mathrm{LL}}$. See text for discussion.

same airway generation number, on the mean. However, there was some variation, and sometimes $\mathrm{CP}$ were identified at different airway sites. The distance between $\mathrm{CP}$ on air and $\mathrm{CP}$ on $\mathrm{He} / \mathrm{O}_{2}$ ranged from $0.5 \mathrm{~cm}$ to $2.5 \mathrm{~cm}$. Most often $\mathrm{CP}$ on $\mathrm{He} /$ $\mathrm{O}_{2}$ were upstream to air, but the opposite also occurred. $\mathrm{CP}$ locations at different airway sites occurred in $\sim 20 \%$ of the cases in group $\mathrm{C}$, and more frequently, $\sim 50 \%$ of the cases in group E. The relevant pressure parameters on $\mathrm{He} / \mathrm{O}_{2}$ are shown in Table V. Measurements of $P *$ and $P_{\mathrm{E}} *$ on $\mathrm{He} / \mathrm{O}_{2}$ were not significantly different compared with those on air. As shown in Table IV, $A *$ and $K$ were not different on air and $\mathrm{He} / \mathrm{O}_{2}$ in the respective groups. In group $\mathrm{C}, P \mathrm{Pr}$ at $V_{\mathrm{VH}}$ and $V_{\mathrm{H}}$ were slightly

Table III. Pfr and Pca Pressure Losses from Alveoli to $\mathrm{CP}$ on Air and $\mathrm{He}_{2} \mathrm{O}_{2}$ in Groups $\mathrm{E}$ and $\mathrm{C}$

\begin{tabular}{|c|c|c|c|c|}
\hline \multirow[b]{2}{*}{$V_{\mathrm{L}}$} & \multicolumn{2}{|l|}{ Group $E$} & \multicolumn{2}{|l|}{ Group C } \\
\hline & Pfr & $P$ ca & Pfr & $P$ ca \\
\hline \multicolumn{5}{|l|}{ Air } \\
\hline$V_{\mathrm{VH}}$ & $1.2 \pm 4.6$ & $5.3 \pm 5.7^{*}$ & $5.7 \pm 6.4$ & $14.1 \pm 3.7$ \\
\hline$V_{\mathrm{H}}$ & $0.9 \pm 1.3$ & $2.4 \pm 0.8^{*}$ & $5.3 \pm 5.3$ & $14.3 \pm 1.8$ \\
\hline$V_{M}$ & $0.4 \pm 0.6$ & $2.4 \pm 1.4$ & $2.2 \pm 2.5$ & $2.9 \pm 0.7$ \\
\hline$V_{\mathrm{LL}}$ & $0.5 \pm 0.7$ & $1.6 \pm 1.4$ & $0.9 \pm 1.7$ & $4.3 \pm 2.6$ \\
\hline \multicolumn{5}{|l|}{$\mathrm{He} / \mathrm{O}_{2}$} \\
\hline$V_{\mathrm{VH}}$ & $2.5 \pm 4.4$ & $5.3 \pm 6.3^{*}$ & $7.5 \pm 1.1$ & $13.5 \pm 4.0$ \\
\hline$V_{\mathbf{H}}$ & $1.5 \pm 3.9$ & $2.7 \pm 2.3^{*}$ & $6.9 \pm 5.3$ & $16.4 \pm 2.3$ \\
\hline$V_{M}$ & $1.0 \pm 1.5$ & $2.0 \pm 1.7$ & $2.3 \pm 4.0$ & $3.6 \pm 1.9$ \\
\hline$V_{\mathrm{LL}}$ & $1.0 \pm 2.1$ & $1.1 \pm 0.6$ & $1.4 \pm 2.8$ & $3.4 \pm 1.6$ \\
\hline
\end{tabular}

Values are given as mean $( \pm \mathrm{SD})$.

${ }^{*} P<0.01$, group $\mathrm{E}$ vs. group $\mathrm{C}$. increased on $\mathrm{He} / \mathrm{O}_{2}$, and tended that way in group $\mathrm{E}$ (see Table III).

\section{Discussion}

The mechanical and histological changes produced in the papain model were typical of pan-acinar pulmonary emphysema. The changes in $\dot{V}$ max were examined in the context of wave-speed theory. To locate $\mathrm{CP}$ at a given $V_{\mathrm{L}}$, an airway site was identified at which lateral pressure did not vary with reservoir pressure, but slightly downstream lateral transmural pressure became relatively more negative and varied with reservoir pressure. Elliott and Dawson (11) used identical criteria in identifying chokepoints when testing wave-speed theory. Thus, in canine tracheas

Table IV. A* and $K$ at the Choke Point on Air and $\mathrm{He} / \mathrm{O}_{2}$ in the Two Groups

\begin{tabular}{clllll}
\hline & $\mathrm{A} *\left(\mathrm{~cm}^{2}\right)$ & & & $\mathrm{K}\left(\mathrm{cm}^{2} / \mathrm{cm} \mathrm{H}_{2} \mathrm{O}\right)$ & \\
\cline { 2 - 3 } \cline { 5 - 6 }$V_{\mathrm{L}}$ & Group E & Group C & & Group E & Group C \\
\hline Air & & & & \\
$V_{\mathrm{VH}}$ & $1.35 \pm 0.43 \ddagger$ & $2.50 \pm 0.43$ & $0.24 \pm 0.18$ & $0.12 \pm 0.05$ \\
$V_{\mathrm{H}}$ & $0.84 \pm 0.32^{*}$ & $2.22 \pm 0.42$ & $0.25 \pm 0.25(n=5)$ & $0.09 \pm 0.04$ \\
$V_{\mathrm{M}}$ & $0.59 \pm 0.22^{*}$ & $4.19 \pm 1.36$ & $0.21 \pm 0.23^{*}(n=4)$ & $0.74 \pm 0.63 \S$ \\
$V_{\mathrm{L}}$ & $0.34 \pm 0.28^{*}$ & $1.76 \pm 1.28$ & $0.52(n=1)$ & $0.39 \pm 0.45$ \\
$\mathrm{He} / \mathrm{O}_{2}$ & & & & \\
$V_{\mathrm{VH}}$ & $1.49 \pm 0.61 \ddagger$ & $2.46 \pm 0.6$ & $0.50 \pm 0.59$ & $0.13 \pm 0.10$ \\
$V_{\mathrm{H}}$ & $0.79 \pm 0.39^{*}(n=5)$ & $2.11 \pm 0.34$ & $0.17 \pm 0.13(n=5)$ & $0.08 \pm 0.03$ \\
$V_{\mathrm{M}}$ & $0.65 \pm 0.45^{*}$ & $3.80 \pm 1.66$ & $0.37 \pm 0.28^{*}(n=5)$ & $0.88 \pm 0.70 \S$ \\
$V_{\mathrm{LL}}$ & $0.33 \pm 0.18^{*}$ & $1.94 \pm 1.0$ & $0.43 \pm 0.52(n=2)$ & $0.63 \pm 0.47(n=3)$ \\
& & & & \\
\hline
\end{tabular}

Values are given as mean $( \pm \mathrm{SD})$.

${ }^{*} P<0.01$, group $\mathrm{C}$ vs. group $\mathrm{E}$.

$\ddagger P<0.05$, group $\mathrm{C}$ vs. group $\mathrm{E}$.

$\S P<0.01$, group $\mathrm{C}\left(V_{\mathrm{H}}\right.$ and $V_{\mathrm{VH}}$ vs. $\left.V_{\mathrm{M}}\right)$. 


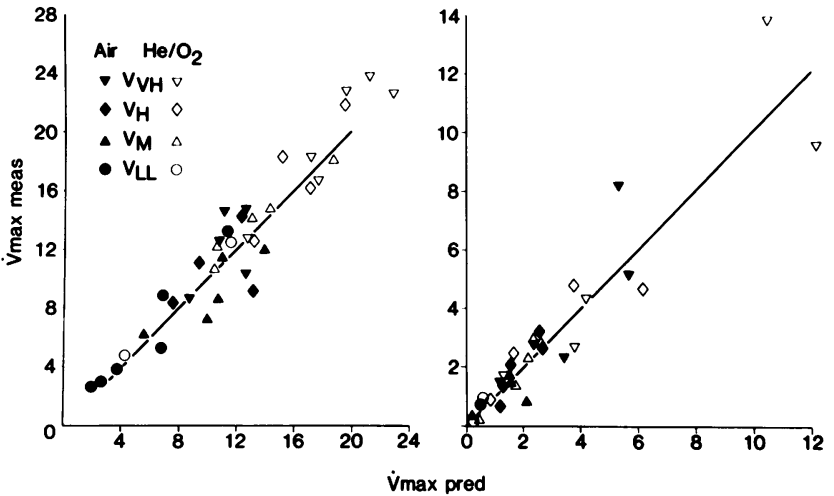

Figure 5. Measured maximum expiratory flow rates ( $\dot{V} \max$ meas) are plotted against those predicted ( $\dot{V}$ max pred) in group $C(l e f t)$ and group $\mathrm{E}(r i g h t)$. $\dot{\mathrm{m}} \mathrm{max}$ pred was derived from the wave-speed equation in which the respective values of $A *$ and $K$ obtained in the individual experiments at each $V_{L}$ were used. The constant $\mathrm{q}$ in the wave-speed equation was taken to be one. The lung volumes $\left(V_{\mathrm{VH}}\right.$, $V_{\mathrm{H}}, V_{\mathrm{M}}, V_{\mathrm{LL}}$ ) corresponded approximately to $65,50,35$, and $15 \%$ VC. Closed symbols indicate the results obtained on air while open symbols indicate those on $\mathrm{He} / \mathrm{O}_{2}$. Solid line represents the line of identity.

and elastic tubes, they obtained flow limitation by varying downstream pressure with a negative-pressure reservoir. At a given upstream pressure, the choke-point was determined as that airway site just upstream from which lateral transmural airway pressure remained constant, once maximum flow was attained. Similarly, Pedersen et al. (23) also located CP in canine lungs. In addition to the criteria already described to locate $\mathrm{CP}$, these investigators used measurements of lateral airway pressure, $P$ ca, and $\dot{V}$ max obtained at different airway sites to determine

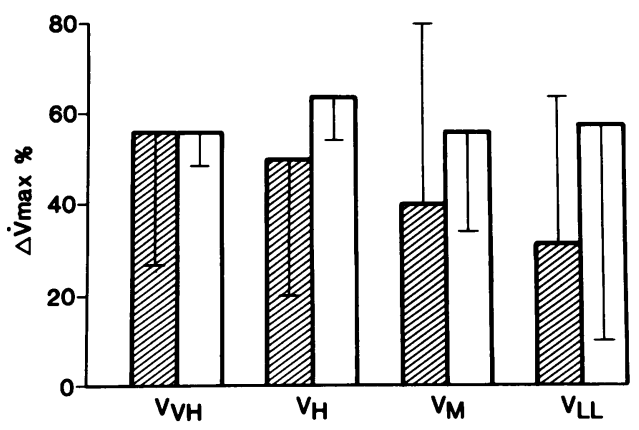

Figure 6. Mean ( $\pm \mathrm{SD})$ responses to breathing $\mathrm{He} / \mathrm{O}_{2}(\Delta \dot{V} \max \%)$ at the four lung volumes $\left(V_{\mathrm{VH}}, V_{\mathrm{H}}, V_{\mathrm{M}}\right.$, and $\left.V_{\mathrm{LL}}\right)$ in group $\mathrm{E}$ (striped boxes) and group $C$ (empty boxes). Since at each $V_{\mathrm{L}}$, the individual responses were used to calculate the mean values in this figure, the respective values may be slightly different from those obtained from mean $\dot{V} \max$ on $\mathrm{He} / \mathrm{O}_{2}$ divided by mean $\dot{V} \max$ on air found in Tables $\mathrm{V}$ and II, respectively.
Table V. Values of Maximum Expiratory Flow (V́max [Liters per Second]) and Relevant Pressure Measurements on $\mathrm{He} / \mathrm{O}_{2}$ in Groups $\mathrm{E}$ and $\mathrm{C}$

\begin{tabular}{lllll}
\hline$V_{\mathrm{L}}$ & \multicolumn{1}{l}{$P_{\mathrm{el}}$} & \multicolumn{1}{l}{$V_{\max }$} & $P_{\mathrm{E}^{*}}$ & $P_{*}$ \\
\hline Group E & & & & \\
$\mathrm{V}_{\mathrm{VH}}$ & $4.6 \pm 0.7^{*}$ & $6.3 \pm 4.6^{*} \ddagger$ & $2.1 \pm 4.5$ & $-3.2 \pm 7.9^{*}$ \\
$\mathrm{~V}_{\mathrm{H}}$ & $3.4 \pm 1.5^{*}$ & $2.9 \pm 1.7^{*} \ddagger$ & $1.9 \pm 4.0$ & $-0.8 \pm 2.8^{*}$ \\
$\mathrm{~V}_{\mathrm{M}}$ & $2.3 \pm 1.3$ & $1.7 \pm 1.2^{*} \ddagger$ & $1.3 \pm 2.4$ & $-0.7 \pm 1.6$ \\
$\mathrm{~V}_{\mathrm{LL}}$ & $1.3 \pm 0.8$ & $0.7 \pm 0.4^{*} \ddagger$ & $0.3 \pm 2.6$ & $0.8 \pm-2.8$ \\
Group C & & & & \\
$\mathrm{V}_{\mathrm{VH}}$ & $10.9 \pm 5.8$ & $19.2 \pm 4.6 \ddagger$ & $3.4 \pm 1.6$ & $-10.1 \pm 4.6$ \\
$\mathrm{~V}_{\mathrm{H}}$ & $8.0 \pm 3.9$ & $18.5 \pm 4.4 \ddagger$ & $1.1 \pm 1.4$ & $-15.3 \pm 2.7$ \\
$\mathrm{~V}_{\mathrm{M}}$ & $4.8 \pm 2.8$ & $14.1 \pm 2.9 \ddagger$ & $2.5 \pm 1.3$ & $-1.1 \pm 1.5$ \\
$\mathrm{~V}_{\mathrm{LL}}$ & $2.9 \pm 2.6$ & $6.9 \pm 3.3 \ddagger$ & $1.5 \pm 0.9$ & $-1.9 \pm 0.8$ \\
\hline
\end{tabular}

$V_{\mathrm{VH}}, V_{\mathrm{H}}, V_{\mathrm{M}}$, and $V_{\mathrm{LL}}$ correspond to lung volumes $\left(V_{\mathrm{L}}\right)$ at which $\mathrm{CP}$ were identified.

$P *$ and $P_{\mathrm{E}} *$ are lateral and end-on transmural pressures, respectively, ( $\mathrm{cm} \mathrm{H}_{2} \mathrm{O}$, mean $\pm \mathrm{SD}$ ).

${ }^{*} P<0.01$, group $\mathrm{E}$ vs. group $\mathrm{C}$.

$\ddagger P<0.01 \mathrm{HeO}_{2}$ vs. air in the respective groups.

the airway site where local wave-speed was reached. Their results describing choke-point area and location, $P *$, and $P_{E^{*}}$ in normal canine lungs were comparable to those obtained in the present study at similar lung volumes. Their results also compared well with those reported in a previous study in which a retrograde catheter was used to identify wave-speed parameters (14). Indeed, the wave-speed parameters obtained in this study with the Pitotstatic tube and retrograde catheter techniques gave similar findings. This was also the case when in a canine model of bronchoconstriction the two techniques were compared (24). However, wave-speed parameters identified by either technique should be viewed cautiously. Although the location of CP may be rather precise this way, the exact pressure at $\mathrm{CP}$ may be sometimes difficult to determine. Considerations with respect to the limitations of these techniques are addressed further below.

Mechanism of the reduction in $\dot{V}$ max. According to wavespeed theory, $\dot{V} \max$ is reached when a choke-point occurs in an airway generation $(10,11)$. In group $C, C P$ were identified at the trachea at $V_{\mathrm{VH}}$ and $V_{\mathrm{H}}$ and in the lobar bronchi at $V_{\mathrm{M}}$ and $V_{\mathrm{LL}}$. In group $\mathrm{E}$, however, $\mathrm{CP}$ were found at sublobar to segmental bronchi (1-cm diam). Thus, in emphysematous lungs, tube wave-speed occurred at a more peripheral location. CP remained at this airway site over most of the vital capacity, and further upstream movement occurred only at the lower lung volumes and only in two experiments (see Fig. 4). In a previous study, Macklem et al. (8) demonstrated that airflow obstruction occurred at two airway sites in patients with chronic bronchitis and emphysema. In all patients, airflow obstruction occurred at lobar bronchi, while in three, a resistive pressure drop also 
occurred in upstream airways. The results of Macklem et al. (8) were similar to those obtained in the present study. In most dogs, flow limitation occurred at sublobar bronchi, whereas in dog No. 3 a resistive pressure drop also occurred in upstream airways. Macklem et al. (8) found that at low lung volumes, lobar bronchi no longer limited flow, indicating peripheral movement of the flow limiting site. As previously described, slight peripheral movement of the flow-limiting site occurred only in two dogs in this study.

Pulmonary emphysema resulted in a severe reduction in $\dot{V}$ max. Changes in lung mechanical properties were such that $\mathrm{CP}$ occurred in a more peripheral airway at a lower choke-point area and $\dot{V}$ max. In terms of the wave-speed equation, $\dot{V} \max$ decreased at each $V_{\mathrm{L}}$ because choke-point area decreased. The relative effect of changes in $K$ at each $V_{\mathrm{L}}$ were variable. According to wave-speed theory, each bronchial generation determines its own maximal flow $(10,11)$. For a given generation, there exists a unique relationship between local maximal flow and local total pressure on the one hand and local pressure-area relationship on the other. Overall, $\dot{V} \max$ will be reached for the lowest value of $(A * / K)^{1 / 2}$, that is, when tube wave-speed is achieved in some airway generation. The factors determining local maximal flow are the local total pressure and the pressurearea behavior of the airway. Local total pressure is determined by the $P$ el and the $P$ fr (12). In this study, total pressure at the choke-point was estimated by $P_{\mathrm{E}^{*}}\left(P \mathrm{el}-P \mathrm{fr}=P_{\mathrm{E}} *\right)$. In the frictionless condition, $P_{\mathrm{E}} *$ would equal $P$ el.

As shown in Table II, Pel decreased in group E. Thus, one mechanical change in emphysema was a reduction in Pel. If $\mathrm{CP}$ remained at the same airway site, then a reduction $P$ el per se, by reducing airway total pressure, would result in a reduction in $\dot{V}$ max. However, a reduction in Pel would also change the distribution of the pressure drop from alveoli along the airway. Peripheral airways, otherwise distended in healthy lungs, would now be relatively narrowed. A relative narrowing in upstream airways may result in tube wave-speed occurring there. In group C, $P$ lat- $P$ pl and $P$ end- $P$ pl were also measured at sublobar bronchi at the four $V_{\mathrm{L}}$. Cross sectional areas at these bronchi were then calculated. These results are listed in Table VI to be compared with Table IV. Cross-sectional areas of sublobar bronchi in group $\mathrm{C}$ were much higher than in group $\mathrm{E}$, and at the four $V_{\mathrm{L}}$ that were examined they ranged from about 3 to 10 times as much. Thus, a reduction in Pel, by reducing cross-sectional area in upstream airways, contributed (at least in part, see below) to $\mathrm{CP}$ occurring more peripherally.

While the decrease in Pel was one of the factors that resulted in the reduction in $\dot{V} \max$, other mechanical changes may have also contributed. In group $\mathrm{E}, P \mathrm{el}$ at $V_{\mathrm{VH}}$ and $V_{\mathrm{H}}$ measured 4.5 cm $\mathrm{H}_{2} \mathrm{O}$ and $3.7 \mathrm{~cm} \mathrm{H}_{2} \mathrm{O}$, respectively (see Table II). These values were similar to those obtained in group $C$ at $V_{M}(4.7 \mathrm{~cm}$ $\left.\mathrm{H}_{2} \mathrm{O}\right)$ and $V_{\mathrm{LL}}\left(2.9 \mathrm{~cm} \mathrm{H}_{2} \mathrm{O}\right)$. Yet, for comparable $P$ el, $\dot{V} \max$ was still much lower in group E. As shown in Table II, at a Pel of $\sim 5.0 \mathrm{~cm} \mathrm{H} \mathrm{H}_{2} \mathrm{O}, \dot{V}$ max measured 9.2 liters/s in group $\mathrm{C}$ com-
Table VI. A and Pressure Measurements at Sublobar Bronchi in Group C

\begin{tabular}{llrr}
\hline & $A$ & $P$ end-Ppl & \multicolumn{1}{c}{$P$ lat-Ppl } \\
\hline$V_{\mathrm{VH}}$ & $6.2 \pm 2.7$ & $6.9 \pm 2.0$ & $4.1 \pm 1.7$ \\
$V_{\mathrm{H}}$ & $6.5 \pm 4.6$ & $5.5 \pm 1.7$ & $2.2 \pm 2.7$ \\
$V_{\mathrm{M}}$ & $5.0 \pm 3.7$ & $3.0 \pm 1.8$ & $0.5 \pm 1.9$ \\
$V_{\mathrm{LL}}$ & $1.4 \pm 0.7$ & $2.0 \pm 1.2$ & $-0.5 \pm 3.2$ \\
\hline
\end{tabular}

$P$ lat- $P$ pl and $P$ end- $P$ pl represent transmural lateral and end-on pressures, respectively (mean $\pm \mathrm{SD}, \mathrm{cm} \mathrm{H}_{2} \mathrm{O}$ ). $A$ is given in square centimeters.

pared with 3.9 liters/s in group E. At a $P$ el of $\sim 3 \mathrm{~cm} \mathrm{H}_{2} \mathrm{O}$ $\dot{V}$ max measured 4.7 liters/s in group $\mathrm{C}$ vs. 1.9 liters/s in group E. If $P$ el were the only factor responsible for the decrease in $\dot{V}$ max, then a reduction in $P$ el from $\sim 10 \mathrm{~cm} \mathrm{H}_{2} \mathrm{O}$ to $5 \mathrm{~cm} \mathrm{H}_{2} \mathrm{O}$ should have decreased $\dot{V} \max$ from 12.3 lps (found at $V_{\mathrm{VH}}$ in group $\mathrm{C}$ ) to 9.2 liters/s (found in $V_{\mathrm{M}}$ in group $\mathrm{C}$, see Table II). Thus, about one-third to one-half the reduction in $\dot{V}$ max could be explained by the decrease in Pel. Other mechanical changes that may have contributed to the reduction in $\dot{V} \max$ were increases in frictional resistance from alveoli to sublobar bronchi and changes in the pressure area behavior of the airways.

The destruction of lung tissue in pulmonary emphysema may decrease the number and elasticity of the radial attachments from the parenchyma to the airway, and in this way may decrease airway stability $(2,4,5,27)$. In terms of wave-speed theory, a decrease in airway stability would lower $\dot{V} \max$ by decreasing cross-sectional area for a given transmural airway pressure, and by relatively increasing airway compliance a decrease might also be expected. Alternatively, altered bronchial pressure-area behavior could result from a relative increase in peribronchial interstitial pressure. Thus, for a given lateral intraluminal pressure, cross-sectional area in PE would be smaller than in healthy lungs, because true transmural pressure (i.e., Plat-peribronchial pressure) would be less. Indeed, there is some evidence to suggest that changes in pressure airway behavior did occur in group $\mathrm{E}$. In group $\mathrm{E}$, at $V_{\mathrm{VH}}$ and $V_{\mathrm{H}}, P_{\mathrm{E}} *$ measured $3.3 \mathrm{~cm} \mathrm{H}_{2} \mathrm{O}$ (see Table II) and $2.8 \mathrm{~cm} \mathrm{H} \mathrm{H}_{2} \mathrm{O}$, respectively. These values were similar to the end-on pressures $(P$ end- $P$ pl) measured in sublobar bronchi in group $\mathrm{C}$ at approximately the same $P$ el values, where $P$ end$P$ pl measured $3.0 \mathrm{~cm} \mathrm{H}_{2} \mathrm{O}$ at $V_{\mathrm{M}}$ (see Table VI) and $2.0 \mathrm{~cm}$ $\mathrm{H}_{2} \mathrm{O}$ at $V_{\mathrm{LL}}$. Pend- $P$ pl and $P_{\mathrm{E}} *$ are both estimates of total airway pressure, where $P_{\mathrm{E}}$ is the total pressure at the choke-point (see Methods). In terms of wave-speed theory, therefore, respective total pressures in sublobar bronchi were the same at $V_{\mathrm{VH}}$ and $V_{\mathrm{H}}$ in group $\mathrm{E}$ and at $V_{\mathrm{M}}$ and $V_{\mathrm{LL}}$ in group $\mathrm{C}$. Accordingly, for $V_{\mathrm{L}}$ with similar $P$ el and total airway pressures, $\mathrm{CP}$ occurred at sublobar bronchi in group E, but not in group C. CP not only occurred slightly more downstream (i.e., at lobar bronchi) in group $\mathrm{C}$, but more importantly at a much higher $\dot{V} \max$. In 
terms of wave-speed theory, for these findings to occur, a change in bronchial pressure-area behavior would be necessary if the difference in area cannot be accounted for by differences in distending pressure $(10,11)$. The results show that for a given transmural airway pressure, cross-sectional areas at sublobar bronchi were much larger in group $\mathrm{C}$ than in group $\mathrm{E}$. In group E, at $V_{\mathrm{H}}$, Plat-Ppl measured $0.4 \mathrm{~cm} \mathrm{H}_{2} \mathrm{O}$ (see Table II) and cross-sectional area was $0.84 \mathrm{~cm}^{2}$ (see Table IV). In group $\mathrm{C}$, at $V_{\mathrm{M}}$, Plat- $P$ pl at sublobar bronchi measured $0.5 \mathrm{~cm} \mathrm{H}_{2} \mathrm{O}$ (see Table VI) and the cross-sectional area was $5.0 \mathrm{~cm}^{2}$. These findings would suggest therefore that a change in bronchial pressurearea behavior played a role in the reduction in $\dot{V} \max$.

Increased frictional resistance to sublobar bronchi in group E may have additionally contributed to the reduction in $\dot{V}$ max. Frictional resistances to sublobar bronchi were calculated in the two groups. At comparable $P$ el, frictional resistances were higher in group E. At a $P$ el of $\sim 5.0 \mathrm{~cm} \mathrm{H}_{2} \mathrm{O}$, frictional resistance to sublobar bronchi measured $0.31 \mathrm{~cm} \mathrm{H}_{2} \mathrm{O} /$ liters per $\mathrm{s}$ in group $\mathrm{E}$ (from $P$ el- $P_{\mathrm{E}^{*}}$ divided by $\dot{V} \mathrm{max}$ in Table II) and $0.18 \mathrm{~cm}$ $\mathrm{H}_{2} \mathrm{O}$ /liters per $\mathrm{s}$ in group $\mathrm{C}$ \{from $(P \mathrm{el}-P$ end- $P$ pl) divided by $\dot{V}$ max; where $P$ el and $\dot{V} \max$ are from Table II and $P$ end- $P$ pl is from Table VI\}. At a $P$ el of $\sim 3 \mathrm{~cm} \mathrm{H}_{2} \mathrm{O}$, the respective values were $0.47 \mathrm{~cm} \mathrm{H}_{2} \mathrm{O} /$ liters per $\mathrm{s}$ and $0.19 \mathrm{~cm} \mathrm{H}_{2} \mathrm{O} /$ liters per s. The effect of an increase in frictional resistance would be to further reduce total pressure. As shown in Tables III and VI, at a $P$ el of $\sim 5 \mathrm{~cm} \mathrm{H}_{2} \mathrm{O}\left(V_{\mathrm{VH}}\right), P$ fr to sublobar bronchi measured $\sim 1.2 \mathrm{~cm} \mathrm{H}_{2} \mathrm{O}$ in group $\mathrm{E}$ and $1.7 \mathrm{~cm} \mathrm{H}_{2} \mathrm{O}$ in group $\mathrm{C}$ \{from $P$ el $-(P$ end- $P$ pl $)\}$. At the lower $P$ el, $P$ fr measured $0.9 \mathrm{~cm} \mathrm{H}_{2} \mathrm{O}$ in group $\mathrm{E}$ and $0.9 \mathrm{~cm} \mathrm{H}_{2} \mathrm{O}$ in group $\mathrm{C}$. Thus, changes in $\dot{V} \max$ and frictional resistances were such that the frictional pressure losses to these bronchi were about the same, even though $\dot{V} \max$ was substantially reduced in group E. If frictional resistance did not increase in group $\mathrm{E}$, then $P f r$ would have been relatively lower, and $P_{\mathrm{E}^{*}}$ and $\dot{V}$ max would have been somewhat higher. It is worthwhile noting, however, that most of the increase in frictional resistance occurred in $\operatorname{dog} 3$, and in some experiments, frictional pressure losses were trivial. Thus, in an individual experiment, an increase in frictional resistance may or may not have been a factor.

In terms of the wave-speed equation, the decrease in $\dot{V} \max$ in group $\mathrm{E}$ was due to a relative decrease in choke-point area. At some lung volumes, $K$ increased, which also contributed to a lower $\dot{V}$ max. At $V_{M}$, however, $K$ decreased (see Table IV). At $V_{M}$, the relative effect of the change in $A *$ was much greater than that in $K$, so that $\dot{V}$ max decreased substantially. Moreover, note that $K$ is not an index of bronchial pressure-area behavior at anatomical comparable locations, but the compliance of the airway at the measured $P *$. Thus, at the respective $V_{\mathrm{L}}$, changes in $K$ were due to a choke-point occurring at more peripheral bronchi, where at the $P *$ measured, airway compliance increased or decreased in group $\mathrm{E}$. In terms of the wave-speed variables, at $V_{\mathrm{VH}}, A *$ decreased from $2.5 \mathrm{~cm}^{2}$ in group $\mathrm{C}$ to $1.35 \mathrm{~cm}^{2}$ in group $\mathrm{E}$ or $\sim 45 \%$. The respective values of $K$ increased from
$0.12 \mathrm{~cm}^{2} / \mathrm{cm} \mathrm{H}_{2} \mathrm{O}$ to $0.24 \mathrm{~cm}^{2} / \mathrm{cm} \mathrm{H}_{2} \mathrm{O}$ or $\sim 100 \%$ (see Table IV). As determined by the respective variables in the wave-speed equation in group $C\left(2.5^{3} / 0.12\right)^{1 / 2}$ vs. group $\mathrm{E}\left(1.35^{3} / 0.24\right)^{1 / 2}$, the predicted reduction in $\dot{V} \max$ would be to $\sim 28 \%$ of control. Thus, predicted $\dot{V} \max$ would be $(12.4$ liters/s $\times 0.28)$ or 3.5 liters/s, which as indicated in Table II was close to that which was measured 3.9 liters/s (see Fig. 5 for individual values). Similarly, at $V_{\mathrm{H}}$, again calculated from the variables in the wavespeed equation, the predicted reduction in $\dot{V}$ max would be close to 0.14 of control, or $0.14 \times 11.3$ liters $/ \mathrm{s}=1.6$ liters $/ \mathrm{s}$. At $V_{\mathrm{M}}$, the predicted $\dot{V} \max$ would be $(0.1 \times 9.2$ liters/s $)$ or 0.92 liters/ $\mathrm{s}$, again close to that which was measured (1.1 liters/s). Therefore, as estimated from the Pitot-static tube measurements, the changes in $A *$ and $K$ in terms of the wave-speed equation predicted the measured $\dot{V}$ max. In Fig. 5, measured $\dot{V} \max$ was plotted against that estimated ( $\dot{V}$ max pred) for the individual experiments at each $V_{\mathrm{L}}$. The wave-speed variables obtained in the respective experiments were used to estimate predicted $\dot{V} \max$.

The results in this study indicate that in PE, the mechanism of the reduction of $\dot{V}$ max was complex, and that this reduction was dependent upon the interaction of changes in Pel, viscous pressure losses, and bronchial pressure-area behavior. In terms of the wave-speed equation, at the $V_{\mathrm{L}}$ examined, a decrease in $A *$ was the most important factor contributing to this reduction. However, at other lung volumes, in some experiments, it appeared that $A *$ could remain the same or increase, compared with control, while the mechanism of the reduction of $\dot{V} \max$ in these instances was totally due to a relative increase in $K$. Indeed, in a canine model of bronchiolitis obliterans, the latter findings were observed (28). At $\sim 50 \%$ VC, $\dot{V} \max$ decreased from 9.2 liters/s in the control group to 7.3 liters/s in the bronchiolitis group. CP were identified at the trachea in the former group and at lobar bronchi in the latter. $A *$ measured $2.5 \mathrm{~cm}^{2}$ in the control group and $2.8 \mathrm{~cm}^{2}$ in the bronchiolitis group, and the respective values of $K$ were $0.16 \mathrm{~cm}^{2} / \mathrm{cm} \mathrm{H}_{2} \mathrm{O}$ and 0.44 $\mathrm{cm}^{2} / \mathrm{cm} \mathrm{H}_{2} \mathrm{O}$. Thus, the mechanism of the reduction in $\dot{V} \max$ in this instance was a relative increase in $K$, as CP shifted to lobar bronchi. At the $P *$ measured, bronchial cross-sectional area was larger and the airway more compliant than in control. In terms of the wave-speed equation, $\dot{V} \max$ decreased because the increase in $K$ was greater than that in $A *$. In the present study, the decreases in recoil pressures were substantial. Conceivably, with lesser decreases or at other $V_{L}$, the mechanism of the decrease in $\dot{V}$ max, in terms of the wave-speed factors, could be similar to that found in the bronchiolitis model.

Response to $\mathrm{He} / \mathrm{O}_{2}$ breathing. At the measured $V_{\mathrm{L}}, \Delta \dot{V} \max$ did not decrease significantly in group $\mathrm{E}$, although on the mean, it did decrease at the lower $V_{\mathrm{L}}$. Dosman and Elliott (10) suggested that breathing a $\mathrm{He} / \mathrm{O}_{2}$ gas mixture may be of use in detecting obstruction of the small airways in smokers at a stage when $\dot{V}$ max on air was normal. As a result of small airways obstruction, equal pressure points (EPP) would move upstream where in small airways laminar flow would occur and where cross-sec- 
tional area would be large. According to Mead et al. (6), EPP represented the airway site where pleural pressure equaled lateral airway pressure. Just downstream from EPP, dynamic compression limiting flow occurred. Accordingly, as EPP moved upstream, density-dependent pressure losses would be reduced and $\Delta \dot{V}$ max would decrease.

In terms of the present study, EPP were defined similarly to the study of Mead et al. and thus would be identified at an airway site where $P$ lat $=P$ pl (i.e., where transmural pressure was zero). EPP on both gases were found upstream and downstream from the $\mathrm{CP}$, the actual airway site where flow became limited. EPP downstream from CP can only occur when flow is limited at positive transmural pressures. This occurred frequently at $V_{\mathrm{VH}}$ and $V_{\mathrm{H}}$ in group $\mathrm{E}$ (see Figs. 2 and 3 , also occurred in reference 28). In terms of EPP rationale, however, $\Delta \dot{V}$ max did not decrease in group $\mathrm{E}$ for the following reasons. $\mathrm{CP}$ remained at relatively central locations over most of the vital capacity. Thus cross-sectional areas at $\mathrm{CP}$ were relatively small, and density dependent $P$ ca still represented a substantial proportion of the pressure drop to CP (see Table III). Further, at least at $\mathrm{CP}$, as determined by the estimated Reynold's numbers at these sites, turbulent flow was present. Although Dosman suggested that in patients with small airways obstruction, EPP would move into airways where cross-sectional area was large and flow laminar, Macklem et al. (8) showed that in patients with emphysema or bronchitis airflow limitation still occurred at lobar bronchi. Accordingly, the findings in the present experiment with respect to loci of flow limitation were similar to those previously reported by Macklem et al. Interestingly, Dosman et al. suggested that when the only mechanical change in the lung was a decrease in $P$ el, $\Delta \dot{V}$ max would not decrease. This intuition may be generally correct.

In two experiments (dogs 2 and 3 ), however, $\Delta \dot{V} \max$ did decrease, and some insight into the mechanism of these decreases may be ascertained from the changes in the wave-speed variables in these dogs. In dog 3, frictional pressure losses to CP accounted for most of the pressure losses. In terms of wave-speed theory, recent studies have shown that while breathing a $\mathrm{He} / \mathrm{O}_{2}$ gas mixture, airway geometry may change $(13,14,29)$. In those studies, EPP on $\mathrm{He} / \mathrm{O}_{2}$ were found upstream to air, and at $\mathrm{He} /$ $\mathrm{O}_{2}$ EPP, airway cross-section on air was greater than on $\mathrm{He} /$ $\mathrm{O}_{2}$. This finding was due to a relative increase in frictional pressure losses on $\mathrm{He} / \mathrm{O}_{2}$. This increase was the result of frictional pressure losses in upstream airways which were less than maximally density dependent and of a higher $\dot{V} \max$ on $\mathrm{He} / \mathrm{O}_{2}$. The net outcome was that during forced expiration a narrower bronchial cross-section occurred on $\mathrm{He} / \mathrm{O}_{2}$. In essence, the effect of gas density on frictional resistance was somewhat offset by a change in airway geometry. Thus, if CP were similarly located on both gas mixtures, then compared with air a relative increase in frictional pressure losses on $\mathrm{He} / \mathrm{O}_{2}$ would also relatively reduce $P_{\mathrm{E}} *$ on $\mathrm{He} / \mathrm{O}_{2}$. With a lower total airway pressure on $\mathrm{He} / \mathrm{O}_{2}$, a relatively lower $A *$ on $\mathrm{He} / \mathrm{O}_{2}$ would also occur. In terms of the wave-speed equation, a relative reduction in $A *$ on $\mathrm{He} / \mathrm{O}_{2}$ would decrease $\Delta \dot{V} \max$ from that maximally predicted on the basis of gas density.

In group $\mathrm{E}$, in most experiments, differences in viscous pressure losses between air and $\mathrm{He} / \mathrm{O}_{2}$ were not large enough for significant changes in $P_{\mathrm{E}} *$ to occur. Therefore, $\Delta \dot{V} \max$ did not decrease, and the wave-speed variables were about the same on both gas mixtures. However, in $\operatorname{dog} 3$, this was not the case, and $\Delta \dot{V}$ max did decrease. At $V_{\mathrm{LL}}, P_{\mathrm{E}} *$ measured $0.25 \mathrm{~cm} \mathrm{H}_{2} \mathrm{O}$ on air and $-4.75 \mathrm{~cm} \mathrm{H}_{2} \mathrm{O}$ on $\mathrm{He} / \mathrm{O}_{2}$. On air $A *$ was $0.14 \mathrm{~cm}^{2}$, and on $\mathrm{He} / \mathrm{O}_{2} 0.086 \mathrm{~cm}^{2}$. A $40 \%$ reduction in $A *$ would reduce $\Delta \dot{V} \max$ to about zero if $K$ did not change. In this experiment, at all $V_{\mathrm{L}}$, frictional pressure losses were much higher on $\mathrm{He} /$ $\mathrm{O}_{2}$, and $P_{\mathrm{E}} *$ and $P *$ on $\mathrm{He} / \mathrm{O}_{2}$ more negative than on air. In fact, on the respective gas mixtures, $P_{\mathrm{E}^{*}}$ and $P *$ were nearly the same, indicating that in this experiment almost the entire pressure drop from alveoli to CP was due to Pfr. It is for this reason that in this experiment comparative wave-speed parameters (particularly $K$ ) on the respective gas mixtures were infrequently obtained. Thus, $\dot{V}$ max measured could not be compared with that predicted from the wave-speed equation. Overall, however, the findings in dog 3 would suggest that the mechanism of the decrease in $\Delta \dot{V}$ max was due to frictional pressure losses on $\mathrm{He} / \mathrm{O}_{2}$ which were relatively greater than on air. Because $P_{\mathrm{E}} *$ on $\mathrm{He} / \mathrm{O}_{2}$ was lower than on air, $A *$ on $\mathrm{He} / \mathrm{O}_{2}$ was also relatively less, and $\Delta \dot{V}$ max decreased.

In $\operatorname{dog} 2, \mathrm{CP}$ on $\mathrm{He} / \mathrm{O}_{2}$ were found $\sim 1 \mathrm{~cm}$ upstream to air although in the same airway generation. $\mathrm{CP}$ located at different airway sites on the two gas mixtures has been previously reported (13). At the respective airway sites, $P_{\mathrm{E}} *$ and $P *$ were again more negative on $\mathrm{He} / \mathrm{O}_{2}$ than on air. In terms of the wave-speed variables, the respective values of $A *$ and $K$ on $\mathrm{He} / \mathrm{O}_{2}$ were 0.21 $\mathrm{cm}^{2}$ and $0.03 \mathrm{~cm}^{2} / \mathrm{cm} \mathrm{H}_{2} \mathrm{O}$ and on air were $0.49 \mathrm{~cm}^{2}$ and 0.08 $\mathrm{cm}^{2} / \mathrm{cm} \mathrm{H}_{2} \mathrm{O}$. Thus, the mechanism of the decrease in $\Delta \dot{V} \max$ in this experiment was similar to dog 3 , in that compared with air, a relative increase in $\mathrm{Pfr}$ on $\mathrm{He} / \mathrm{O}_{2}$ resulted in a relatively reduced $A *$. The respective changes in $A *$ and $K$ on the gas mixtures were such that $\Delta \dot{V}$ max decreased. Moreover, in dog 2 , an additional effect of breathing $\mathrm{He} / \mathrm{O}_{2}$ was to cause $\mathrm{CP}$ to occur at different airway sites.

According to Dosman et al. (16), the low $\Delta \dot{V} \max$ in dog 2 would reflect peripheral airways obstruction. Whereas upstream airways obstruction obviously occurred in $\operatorname{dog} 3$, there was little upstream frictional pressure losses detected in $\operatorname{dog} 2$, and $P_{\mathrm{E}} *$ on air was very near recoil pressure. While intuitively it is difficult to understand that $P$ fr on $\mathrm{He} / \mathrm{O}_{2}$ can be present, when $P$ fr on air was near zero, most likely some amount of upstream frictional pressure losses on air was present in dog 2 that was not detected because of the insensitivity of the measurements used. In favor of this was the value of $R_{\mathrm{L}}$ found in this $\operatorname{dog}$ ( 7.6 liters/s per $\mathrm{cm} \mathrm{H}_{2} \mathrm{O}$ ) which was the highest in group $\mathrm{E}$. However, Meadows et al. (30) reported that in patients with chronic obstructive lung disease, $\Delta \dot{V}$ max obtained at $50 \%$ VC did not correlate well 
with $\dot{V} \max$ on air or with $R_{\mathrm{L}}$. Although Cosio et al. (31) previously reported that small airway pathology in smokers correlated well with the decreases in $\Delta \dot{V}$ max found on pulmonary function testing, Pare et al. (32) recently reported conflicting results. In patients with a forced expiratory volume in $1 \mathrm{~s}\left(\mathrm{FEV}_{1}\right)$ of $<80 \%$ predicted, they found that those patients with the most inflammatory changes in the small airways had the highest $\Delta \dot{V}$ max. Similar results were also obtained in a canine model of bronchiolitis obliterans where evidence of small airways obstruction was histologically observed $(28,33)$. Whereas $\dot{V}$ max on air at $50 \%$ VC decreased significantly in the bronchiolitis model, $\Delta \dot{V}$ max remained high. Accordingly, it is not clear from these studies whether a decrease in $\Delta \dot{V}$ max indeed delineates a particular site of airways obstruction or whether it may occur by chance. During forced deflation with $\mathrm{He} / \mathrm{O}_{2}$, subtle changes in airway geometry occur. These changes could alter the wavespeed variables unpredictably, which in turn would unpredictably alter $\Delta \dot{V}$ max. Alternatively, flow in small airways may be (laminar) density independent in some lesions, and turbulent (density dependent) in others, so that a decrease in $\Delta \dot{V}$ max indicates a peripheral lesion, whereas an unchanged $\Delta \dot{V} \max$ does not necessarily exclude a peripheral lesion.

Using similar methodology, Pedersen et al. (29) studied the mechanism of $\Delta \dot{V}$ max on $\mathrm{He} / \mathrm{O}_{2}$ in normal canine lungs. At $50 \% \mathrm{VC}$, they showed that $A *$ on $\mathrm{He} / \mathrm{O}_{2}$ was significantly less than on air due to increased viscous pressure losses on $\mathrm{He} / \mathrm{O}_{2}$. This finding was associated with a slight decrease in $\Delta \dot{V}$ max from that maximally predicted on the basis of gas density. In the present study, $A *$ on $\mathrm{He} / \mathrm{O}_{2}$ and on air were similar in both groups (see Table IV). At most $V_{\mathrm{L}}, \Delta \dot{V} \max$ was slightly higher in this study and differences in $A *$ and $K$ on the two gas mixtures would not be predicted. Also, in the present study, CP on air and $\mathrm{He} / \mathrm{O}_{2}$ in the control and emphysema groups were sometimes identified at different sites. For instance, in $\operatorname{dog} 1$, at $V_{\mathbf{V H}}$, $\mathrm{CP}$ on $\mathrm{He} / \mathrm{O}_{2}$ were identified $2.5 \mathrm{~cm}$ upstream to air. $A *$ and $K$ on air were $1.54 \mathrm{~cm}^{2}$ and $0.58 \mathrm{~cm}^{2} / \mathrm{cm} \mathrm{H}_{2} \mathrm{O}$, respectively, while the corresponding parameters on $\mathrm{He} / \mathrm{O}_{2}$ were $2.3 \mathrm{~cm}^{2}$ and $1.7 \mathrm{~cm}^{2} / \mathrm{cm} \mathrm{H}_{2} \mathrm{O}$. Thus, the effect of breathing $\mathrm{He} / \mathrm{O}_{2}$ at this lung volume was to cause $\mathrm{CP}$ to occur at an upstream site. Such upstream movement has occurred in other canine models in which $P$ fr was relatively increased $(24,28)$. Thus, compared with air, at the $P *$ measured, cross-sectional area and $K$ were increased on $\mathrm{He} / \mathrm{O}_{2}$. The changes in $A *$ and $K$ were such that $\Delta \dot{V}$ max remained high. Although Pedersen et al. did not report such a mechanism in their experiment, they located CP in only a small number of dogs $(n=5)$. In a previous study (13), CP were identified at the same airway site on air and $\mathrm{He} / \mathrm{O}_{2}$ in seven dogs, while in four other experiments, $\mathrm{CP}$ were identified at different airway sites.

Certainly, in this experiment, the results obtained with the Pitot-static tube should be interpreted in qualitative terms. The Pitot-static tube could cause airflow obstruction, thus changing the wave-speed variables. This was particularly looked for, in that any changes in the flow-volume curve were carefully noted. If there was any question about the Pitot-static tube causing bronchial obstruction, then the Pitot-tube was removed. The flow-volume curve was then repeated and the results were compared. Further, lateral pressure measurements obtained with the retrograde catheter and the Pitot-static tube were quite similar. Because the retrograde catheter was placed into the airway by way of the pleural surface and not by way of the airway opening, there would be less chance of causing airflow obstruction with this technique. Two diameter Pitot-static tubes (2.5 and $1.5 \mathrm{~mm}$ ) were also compared, and the results in each were similar. Thus, it does not appear that the Pitot-static tube caused any measureable artifacts. In another aspect, Pitot-static tube measurements are most accurate when obtained in airways that converge rather than diverge (23). In the latter instance, flow separation occurs and measurements obtained with the Pitotstatic may underestimate cross-sectional area. In this experiment, measurements were obtained upstream from the choke-point where airways converge. Using a similarly designed Pitot-static tube, Pedersen et al. (23) showed that with it positioned in the manner of the present study, estimated cross-sectional areas were relatively accurate. Indeed, Fig. 5 shows that there was a relatively good correlation between measured and predicted $\dot{V} \max$. However, $\dot{V}$ max measured may be close to $\dot{V} \max$ predicted when the variables used to derive $\dot{V}$ max predicted are obtained over some distance in the airway and not exactly at $\mathbf{C P}$.

Moreover, in this model, the emphysema lesion may have occurred variably in the lung, and this may have affected the interpretation of the results since in the analysis the lungs were treated as a unit. In this regard, multiple doses of papain were given to distribute the lesion as widely as possible. In one experiment $(\operatorname{dog} 6)$, to examine for differences between the lower lobes, measurements were taken from the left lower lobe. The results obtained were similar to those from the right lower lobe in the other experiments. Further, in $\operatorname{dog} 6$, the respective pressure-volume curves of the left upper and right lower lobes were compared. The recoil pressures measured from each lobe at comparable $V_{\mathrm{L}}$ were similar. The fraction of trapped gas in each lobe was also similar. Since evidence of severe emphysema was also observed histologically in the upper lobes in group E, it would appear that major differences in the distribution of the emphysema lesion between the lobes were not an important factor in contributing to the results of this study.

However, it is difficult to assess the extent that the papain lesion was distributed variably in each lobe. Compared with the human lesion, intralobar inhomogeneity of the papain lesion was probably present to a lesser degree. Yet, to the extent that intralobar inhomogeneity was present in the model, some parts of the lobe would empty faster than others. Mead et al. (6) pointed out that rapid compartments would contribute to the flow-volume curve early in expiration, whereas the flows obtained at the lower $V_{\mathrm{L}}$ would be influenced by the emptying rates of 
slower units. In this study, different emptying sequences could alter calculation of $P f$, since $P$ el was obtained statically while $P_{\mathrm{E}} *$ was obtained dynamically. Theoretically, this consideration should not affect the calculation of the wave-speed parameters since these parameters were all obtained dynamically and interlobar inhomogeneity (see above) was apparently not substantial. Importantly, one observation in this study that would suggest that intralobar inhomogeneity (and interlobar also) did not contribute to the results in a major way was that the parameters $\dot{V} \max , \Delta \dot{V} \max$, and the wave-speed variables were examined at multiple lung volumes ranging from 66 to $16 \%$ VC. The results were qualitatively similar at all $V_{\mathrm{L}}$. Presumably, any substantial effect of time-constant differences would become apparent when the results obtained at the higher lung volumes were compared with those at the lower ones. Since qualitative differences were not seen at the different $V_{\mathrm{L}}$, this would suggest that there were relatively few normal alveolar units in the lung. This would make any effect of intralobar or interlobar inhomogeneity a less important consideration in altering the conclusions of the study.

Further, although VC and TLC were similar in the two groups at base line, at the end of the study, both values increased in group E. Results in the two groups were compared at similar relative VC. The rationale for analyzing the results in this manner was that the changes in VC and $\dot{V}$ max in group $\mathrm{E}$ were both due to related changes in lung mechanical properties. Since both groups had similar base-line VC, an increase in VC, as one manifestation of PE, would be examined in the context of relative changes in Pel, airway resistance, and airway stability. Thus, the mechanism of the reduction in $\dot{V}$ max appeared best understood when the results were analyzed at similar percentages of VC. When the effect of a larger VC in group E is considered, the reductions in $\dot{V} \max$ would become even more apparent. Indeed, the results can also be compared at similar absolute lung volumes, \% TLC, or Pel, since parameters were analyzed at four $V_{\mathrm{L}}$ over most of the $\mathrm{VC}$ in the two groups (see Tables I, II, and V). The specific comparison would obviously depend upon the question asked. In general, the major conclusions of the study would remain unchanged in each of these analyses. This is because CP were located at approximately the same airway site over most of the $\mathrm{VC}$ in group $\mathrm{E}$ and because the changes in group $\mathrm{E}$ were similar at each $V_{\mathrm{L}}$ examined.

\section{Acknowledgments}

I thank Dr. J. Coalson, Department of Pathology, University of Texas, Health Science Center, San Antonio, TX, for reviewing the lung histology in this study and Dr. L. D. H. Wood for some of the suggestions leading to this study.

The study was supported by grants from the Medical Research Council of Canada, Manitoba Health Research Council, and National Institutes of Health.

\section{References}

1. Christie, R. V. 1934. The elastic properties of the emphysematous lung and their clinical significance. J. Clin. Invest. 13:295-321.

2. Dayman, H. 1951. Mechanics of airflow in health and in emphysema. J. Clin. Invest. 30:1175-1190.

3. Hogg, J. C., P. T. Macklem, and W. M. Thurlbeck. 1968. Site and nature of airways obstruction in chronic obstructive lung disease. N. Engl. J. Med. 278:1355-1360.

4. Butler, J., C. G. Caro, R. Alcala, and A. B. DuBois. 1960. Physiological factors affecting airway resistance in normal subjects and in patients with obstructive respiratory disease. J. Clin. Invest. 39:584591.

5. Liebow, A. A. 1959. Pulmonary emphysema with special reference to vascular changes. Am. Rev. Respir. Dis. 80:67-93.

6. Mead, J., J. M. Turner, P. T. Macklem, and J. B. Little. 1967. The significance of the relationship between lung recoil and maximum expiratory flow. J. Appl. Physiol. 22:95-108.

7. Pride, N. B., S. Permutt, R. L. Riley, and B. Bromberger-Barnea. 1967. Determinants of maximal expiratory flow from the lungs. J. Appl. Physiol. 23:646-662.

8. Macklem, P. T., R. G. Fraser, and W. G. Brown. 1965. Bronchial pressure measurements in emphysema and bronchitis. J. Clin. Invest. 44:897-905.

9. Koblet, H., and F. Wyss. 1956. Das klinische und funktionelle bild des genuinem bronchialkollapses mit lungenemphysem. Helv. Med. Acta. 23:553-560.

10. Dawson, S. V., and E. A. Elliott. 1977. Wave-speed limitation on expiratory flow-a unifying concept. J. Appl. Physiol. Respir. Environ. Exercise Physiol. 43:498-515.

11. Elliott, E. A., and S. V. Dawson. 1977. Test of wave-speed theory of flow limitation in elastic tubes. J. Appl. Physiol. Respir. Environ. Exercise Physiol. 43:516-522.

12. Hyatt, R. E., T. A. Wilson, and E. Bar-Yishay. 1980. Prediction of maximal expiratory flow in excised human lungs. J. Appl. Physiol. Respir. Environ. Exercise Physiol. 48:991-998.

13. Mink, S., M. Ziesmann, and L. D. H. Wood. 1979. Mechanisms of increased maximum expiratory flow during $\mathrm{HeO}_{2}$ breathing in dogs. J. Appl. Physiol. Respir. Environ. Exercise Physiol. 47:490-502.

14. Mink, S., and L. D. H. Wood. 1980. How does $\mathrm{HeO}_{2}$ increase maximum expiratory flow in human lungs? J. Clin. Invest. 66:720-729.

15. Pushpakom, R., J. C. Hogg, A. J. Woolcock, A. E. Angus, P. T. Macklem, and W. M. Thurlbeck. 1970. Experimental papaininduced emphysema in dogs. Am. Rev. Respir. Dis. 102:778-789.

16. Dosman, J., F. Bode, J. Urbanetti, R. Martin, and P. T. Macklem. 1975. The use of a helium-oxygen mixture during maximum expiratory flow to demonstrate obstruction in small airways in smokers. J. Clin. Invest. 55:1090-1099.

17. Takaro, T., and S. McWhite. 1973. Unilateral severe experimental pulmonary emphysema. Am. Rev. Respir. Dis. 108:334-342.

18. Mink, S., R. B. Light, and L. D. H. Wood. 1981. Effect of pneumococcal pneumonia on canine lung mechanics. J. Appl. Physiol. Respir. Environ. Exercise Physiol. 50:283-291.

19. DuBois, A., S. Y. Botelho, G. N. Bedell, R. Marshall, and J. H. Comroe. 1956. A rapid plethysmographic method for measuring thoracic gas volume: a comparison with nitrogen washout method for measuring functional residual capacity in normal subjects. J. Clin. Invest. 35:322326. 
20. Mead, J., and J. C. Whittenberger. 1953. Physical properties of human lungs measured during spontaneous respiration. J. Appl. Physiol. 5:779-796.

21. Lewis, B., L. Tai-hon, and E. Hayfor-Nelson. 1959. The measurement of pulmonary diffusing capacity for carbon monoxide by a rebreathing method. J. Clin. Invest. 38:2073-2086.

22. Macklem, P. T., and J. Mead. 1968. Factors determining maximum expiratory flow in dogs. J. Appl. Physiol. 25:159-169.

23. Pedersen, O. F., B. Thiessen, and S. Lyager. 1982. Airway compliance and flow limitation during forced expiration in dogs. J. Appl. Physiol. Respir. Environ. Exercise Physiol. 52:357-369.

24. Mink, S. 1983. Mechanism of reduced maximum expiratory flow in methacholine-induced bronchoconstriction in dogs. J. Appl. Physiol. Respir. Environ. Exercise Physiol. 55:897-912.

25. Macklem, P. T., and J. Mead. 1967. The resistance of central and peripheral airways measured by a retrograde catheter. J. Appl. Physiol. 22:395-401.

26. Macklem, P. T., and N. J. Wilson. 1965. Measurement of intrabronchial pressure in man. J. Appl. Physiol. 20:653-663.

27. Caldwell, E. J. 1971. Physiologic and anatomic effects of papain on the rabbit lung. J. Appl. Physiol. 31:458-465.
28. Jadue, C., H. Greville, and S. Mink. 1983. Mechanism of reduced maximum expiratory flow in a canine model of broncholitis obliterans. Clin. Invest. Med. 6:77.

29. Pedersen, O. F., R. G. Castile, J. Drazen, and R. Ingram, Jr. 1982. Density dependence of maximum expiratory flow in the dog. $J$. Appl. Physiol. Respir. Environ. Exercise Physiol. 53:397-464.

30. Meadows, J. A., J. R. Rodarte, and R. E. Hyatt. 1980. Density dependence of maximal expiratory flow in chronic obstructive lung disease. Am. Rev. Respir. Dis. 121:47-54.

31. Cosio, M., H. Ghezzo, J. C. Hogg, R. Corbin, M. Loveland, J. Dosman, and P. T. Macklem. 1977. The relationship between structural changes in small airways and pulmonary function tests. $N$. Engl. J. Med. 298:1277-1981.

32. Pare, P. D., L. A. Brooks, C. A. Coppin, J. L. Wright, S. Kennedy, B. R. J. Wiggs, and J. C. Hogg. 1983. Density dependence of maximal expiratory flow and airway pathology in smokers. Am. Rev. Respir. Dis. 127:252.

33. Whitley, L. G., J. J. Coalson, and S. N. Mink. 1982. Bronchiolitis obliterans in a canine model: changes in lung mechanics and an assessment of tests of peripheral airway function. Am. Rev. Respir. Dis. 125(4):189. 